\title{
Thermodynamic consistency in the modeling of speciation in self-complexing electrolytes
}

\author{
Jean-Pierre Simonin ${ }^{*, \dagger, \ddagger}$ \\ †CNRS, UMR 8234, PHENIX, F-75005, Paris, France. \\ $\ddagger$ Laboratoire PHENIX, Sorbonne Universités, UPMC Univ Paris 06, UMR 8234, \\ Université P.M. Curie, F-75005, Paris, France. \\ E-mail: jpsimonin@gmail.com
}

\begin{abstract}
The speciation in aqueous solutions of complexing electrolytes is an important topic in environmental, toxicological and sometimes industrial issues. Its determination requires an estimation of the deviations from ideality which originate from association effects, and excluded volume and electrostatic interactions between the various species. Modeling of such solutions is often based on the use of commonly accepted values for the complex formation constants and of the Davies equation to compute the activity coefficients of the species in solution. In this work, it is shown that this treatment may result in a thermodynamic inconsistency when moderately concentrated solutions of multiply self-complexing salts are considered. This observation casts some doubt on the determination of the speciation in such solutions. Occurrence of this shortcoming is illustrated in the case of zinc and cadmium halides. This finding suggests that the description of deviations from ideality (besides association) should be improved. It also reveals that available complexity constants for some common salts might not always have optimum values in the literature.
\end{abstract}




\section{Introduction}

Aqueous electrolytes are ubiquitous on our planet and have a paramount role on the development and functioning of life. They are present in natural waters (oceans, lakes, sediments), and in the human, animal and plant kingdoms.

A problem intervening oftentimes in environmental, toxicological, and sometimes industrial studies is the issue of speciation in ionic solutions, which results from the tendency of many ions to associate with other species present in solution, in particular with other ions, to form complexes. According to the definition of IUPAC, speciation is "the distribution of an element amongst defined chemical species" in a solution.

Besides adsorption onto colloidal and mineral particles, complexation has a profound influence on the physical chemistry of ions in solution, and thereby on their biological and toxicological behaviour in living bodies and in the environment. ${ }^{1}$ This is particularly true in the case of metal cations which have a prominent role in toxicological issues for instance, and even more so in the case of multivalent metal ions which may have strong binding affinities with other ions. Among others, toxic heavy metal ions of various valencies such as zinc, cadmium, lead or mercury may form a series of complexes through stepwise association with anions like chloride, nitrate, hydroxide, $\ldots{ }^{2,3}$ In water, most metal cations are present in the form of 'aquo-complexes' (or 'aqua cations') in which the first hydration shell is tightly bound to the metal ion. ${ }^{4}$ Strongly polarizing (small and/or highly charged) metal cations may even cleave water molecules in the shell. This hydrolysis reaction then leads to the release of protons in the solution. ${ }^{5,6}$

Complexation of a cation by anions modifies the effective charge of the original cation. It may even transform a cation into an anion, as is e.g. the case of divalent metal ions in presence of chloride ion. Indeed it has been observed that the transference number of the cation may reverse from positive to negative in conductivity or diffusion experiments when the concentration of the chloride ion was increased, thus leading to complexes of high

stoichiometry and negative electric charge. ${ }^{7,8}$ Complexation modifies ion reactivity (to the 
upside or to the downside depending on the type of complex $^{1}$ ) and transport properties, ${ }^{8}$ in environmental ${ }^{9}$ as well as industrial processes (e.g., in the nuclear industry ${ }^{10}$ ). It also increases the total concentration of metal ions in solution, ${ }^{1}$ which has strong consequences on geochemical processes. Last but not least, complexation plays a major role in the biological availability and toxicity of metal ions. In this respect, it should be underlined that complexation decreases the toxicity of metal ions when the free metal ion is the most toxic species, ${ }^{1}$ which is often the case. For this reason, the concentration of free metal cation is a key parameter in toxicological studies. ${ }^{11,12}$

Experimental methods, often coupled with chemical modeling, have been proposed to assess speciation. ${ }^{13}$ Most of these techniques are aimed at the detection of free metal ion concentration. ${ }^{13}$ This is the case of electrochemical methods ${ }^{14}$ for instance. Other techniques include capillary electrophoresis ${ }^{13}$ or permeation liquid membrane. ${ }^{15}$ By and large, speciation is difficult to determine experimentally, if not impossible, because it is not easy to separate the various forms of an element that are generally in kinetically fast chemical equilibrium. Moreover, ionic strength corrections should be applied when the solution is concentrated, but few models are able to provide reliable formulas for concentrated solutions. Consequently it is increasingly difficult to determine speciation in solutions as ionic strength is raised.

Various publicly available and commercial softwares exist which permit estimations of the speciation for many metal ions in aqueous solutions. They are commonly used by researchers in environmental and chemical engineering studies involving many types of electrolytes, including mixtures. One may cite the following ones which have been developed in various countries: MINEQL+, CHESS, SPECIES, MINTEQ, PHREEQC and CHEAQS, ${ }^{16-21}$ the last four being free of charge. The determination of the speciation consists of numerically solving the chemical association equilibria. The softwares rely on previous determinations of the thermodynamic association constants, which can be found in famous books, e.g., in the book by Sillen and Martell, ${ }^{3}$ or in the IUPAC or NIST database. ${ }^{18,22}$ The solution to the chemical equilibria involves formulas for the computation of the activity coefficients of 
the species (free ions and complexes). In the softwares, deviations from ideality (besides association) corresponding to electrostatic interactions are computed using equations of the Debye-Hückel type with a correction, such as the Davies equation ${ }^{23}$ in CHESS, MINTEQ, PHREEQC or CHEAQS, or the specific interaction theory ${ }^{24}$ (SIT) which is available in MINTEQ for more concentrated solutions. The Davies equation gives an expression for the activity coefficient $y_{i}$ of a species of valency $z_{i}$ in a medium of ionic strength $I$ as, $\ln y_{i}=-0.5 z_{i}^{2}[I /(1+\sqrt{I})-0.2 I]$ (see dedicated section below). It coincides with the Debye-Hückel limiting law at high dilution. The term $(-0.2 I)$ was introduced by Davies to account for the rise of the activity coefficient at moderate and high concentrations. It was originally stated that the use of the Davies equation should be limited to concentrations below $0.1 \mathrm{M},{ }^{23}$ but it has been proposed to extend its validity to $1 \mathrm{M} .{ }^{19,25}$

Now, an examination of the literature reveals the following points. The complex formation constants for the metal complexes (assumed to be created in solution) have mainly been determined with the following experimental methods: (i) measurement of mean salt activity coefficient; ${ }^{26,27}$ (ii) cation- ${ }^{28}$ and anion-exchange ${ }^{29}$ on suitable resins; (iii) polarography; ${ }^{30}$ and (iv) solvent extraction. ${ }^{31}$ In (i) activity coefficients were obtained from electromotive force measurements, ${ }^{26,27}$ preferably by utilizing a cell without junction, involving an amalgam electrode. The solutions considered were pure binary solutions of the salt or mixtures of the salt with either a supporting strong electrolyte (like $\mathrm{NaClO}_{4}$ for instance) or another (dissociated) salt with common anion forming complexes with the metal cation.

Experimental data from the different techniques have been interpreted by employing various methods and approximations, which included: in case (i), implementing a particular ad hoc thermodynamic model to account for deviations from ideality, ${ }^{26}$ or approximating activity coefficients of ionic species (free ions and complexes) with experimental values for strong electrolytes at the same ionic strength; ${ }^{27}$ in case (ii), developing an approximate (and involved) treatment for the interpretation of experiments on anion-exchange of metal complexes; ${ }^{32}$ and in cases (iii) and (iv), carrying out experiments at constant ionic strength, ${ }^{30,31}$ 
assuming that activity coefficients of species did not vary, in which case the association constants were 'apparent' constants relative to this particular ionic strength.

When apparent association constants are determined at different ionic strengths, extrapolation of the results to infinite dilution in order to obtain the thermodynamic constants is somewhat uncertain because ionic activity coefficients vary steeply at low concentration as shown by the Debye-Hückel limiting law. ${ }^{33}$ Moreover, the hypothesis of constant activity coefficients at constant ionic strength, which should not be taken for granted in the general case, becomes quite questionable if the calculation of the ionic strength is done on the basis of total dissociation of the salt (at macro concentration), as in the case of zinc and nickel in ref. ${ }^{30}$

This discussion suggests that thermodynamic association constants are not easy to determine, especially when the salt gives weak complexes as is the case of divalent transition metal halides in the series ranging from $\mathrm{Mn}$ to $\mathrm{Zn} .{ }^{33}$ Uncertainty on the values of the thermodynamic complexity constants may be a source of error in the results about speciation. ${ }^{13}$

Another question which seems to have been overlooked in the literature concerns the type of model used to account for deviations from ideality (other than those due to association). As indicated above, softwares generally use the Davies equation (actually a Davies-type equation as shown below), and sometimes also the SIT, to compute the activity coefficients of the species (charged and neutral). It seems that the influence of the utilized formulas on the calculated speciation has not received sufficient attention in the literature.

These observations prompted us to reconsider the problem from the beginning. First, a program was built in FORTRAN to solve the complex formation equilibria for a given model of deviations from ideality and given complexity constants values. The particular case of binary aqueous solutions of zinc and cadmium halides has been considered in this work. The mean salt activity coefficient has been computed for these solutions. Surprisingly enough, as shown below, a thermodynamic inconsistency has been found in some cases when the Davies equation was used. This result led us to replace this latter formula with the mean 
spherical approximation (MSA) model, ${ }^{34}$ which represents a more refined way of describing electrolyte solutions. Furthermore it may be used to higher ionic strengths, of the order of 3M. This property allows one to consider solutions in which larger amounts of complexes of higher stoichiometry are created.

The zinc and cadmium metal ions were chosen in this first work for their importance in environmental issues ${ }^{1}$ and because they are representative of salts producing weak and strong complexes, respectively. Moreover, zinc chloride is an interesting case because various values have been reported for its complexity constants in the abundant literature about this salt. ${ }^{3}$ Also, chloride complexes are important in geochemical studies involving seawater, brines

and hydrothermal solutions ${ }^{1,9,35}$ in which the chloride ion is the major anion (ca. $0.6 \mathrm{M}$ in seawater and up to several molar in natural brines).

The remainder of this paper is organized as follows. In the next section we present the main results that can be found in the literature about the structure and the complexity constants of zinc and cadmium halide complexes. Then, models for the description of the thermodynamics of multi-associating electrolytes (Davies and MSA) are exposed. The fourth section is devoted to the presentation and discussion of the results obtained from these models. The last section presents some concluding remarks and prospects.

\section{Structure of complexes and $\beta_{n}$ values.}

We consider an electrolyte $\mathrm{MX}_{2}$, composed of the divalent metal cation $\mathrm{M}^{2+}$ and halide anion $\mathrm{X}^{-}$, which gives rise to self-complexation according to the following equilibria,

$$
\mathrm{M}^{2+}+n \mathrm{X}^{-} \leftrightarrows \mathrm{MX}_{n}^{2-n} \quad\left(\beta_{n}\right)
$$


in which $\beta_{n}$ is the cumulative complex formation constant (on molarity scale) corresponding to the association of the metal cation with $n$ anions,

$$
\beta_{n}=\frac{y_{n}}{y_{0}\left(y_{X^{-}}\right)^{n}} \frac{C_{n}}{C_{0}\left(C_{X^{-}}\right)^{n}}
$$

where $y$ and $C$ denote activity coefficient and concentration, respectively, on molarity scale. Subscript $n$ denotes the number of anions in the complex $\mathrm{MX}_{n}^{2-n}$. The subscript $n=0$ is used to designate the free metal ion $\mathrm{M}^{2+}$. So, $C_{0} \equiv C\left(\mathrm{M}^{2+}\right)$ and $C_{n} \equiv C\left(\mathrm{MX}_{n}^{2-n}\right)$. In the case of zinc and cadmium halides studied in this work, experimental evidence points to a maximum value of $n=4 .^{3}$

Note that the value of $\beta_{n}$ on molality scale may be deduced ${ }^{7}$ from that on molarity scale by dividing the latter by $d_{0}^{n}$ (with $d_{0}=0.997045 \mathrm{~kg} \mathrm{~L}^{-1}$ the density of pure water at $25^{\circ} \mathrm{C}$ ). The two are therefore numerically very close for any value of $n \leq 4$.

The structure of zinc chloride and bromide complexes in solution has been extensively studied experimentally ${ }^{36-42}$ and numerically. ${ }^{43-46}$ The consistent picture emerging from these studies is one in which the zinc monochloride and monobromide species are mainly outersphere ionic complexes, not covalent compounds; ${ }^{37,38}$ the dichloro and dibromo complexes are hexa-coordinated, similarly to the hydrated $\mathrm{Zn}^{2+}$ ion, and the tri- and tetra-chloro and -bromo complexes are tetra-coordinated. Their formulas are $\mathrm{ZnX}_{2} \mathrm{~W}_{4}^{0},{ }^{37} \mathrm{ZnX}_{3} \mathrm{~W}^{-39,43}$ and $\mathrm{ZnX}_{4}^{2-}, 36,37,42$ with $\mathrm{W}$ standing for the water molecule and $\mathrm{X}$ for $\mathrm{Cl}$ or $\mathrm{Br}$. The change of coordination in the complexes with 3 and 4 chlorides is likely to originate from the fact that it lowers the electrostatic repulsion between the charges on the chlorides as compared to hexacoordinated compounds. ${ }^{43}$ Zinc iodide is very weakly associated in solution. ${ }^{3}$ Nevertheless, a study ${ }^{47}$ suggested that the first iodide complex is hexacoordinated, $\mathrm{ZnIW}_{5}^{+}$, and the higher complexes are tetrahedral, namely $\mathrm{ZnI}_{2} \mathrm{~W}_{2}^{0}, \mathrm{ZnI}_{3} \mathrm{~W}^{-}$and $\mathrm{ZnI}_{4}^{2-} .{ }^{36,42}$ These formulas differ from the chloride and bromide complexes in that the monoiodo complex would be covalent, and the diiodo would be tetracoordinated instead of hexacoordinated. 
Halide complexes of cadmium seem to have been less studied in the literature than those of zinc. Two studies ${ }^{48,49}$ have reported the formation of octahedral $\mathrm{Cd}^{2+}, \mathrm{CdClW}_{5}^{+}$and $\mathrm{CdIW}_{5}^{+}$, and tetrahedral $\mathrm{CdCl}_{2} \mathrm{~W}_{2}^{0}, \mathrm{CdCl}_{3} \mathrm{~W}^{-}, \mathrm{CdCl}_{4}^{2-}$ and $\mathrm{CdI}_{4}^{2-}$ species, similarly to $\mathrm{ZnI} 2$ complexes. Other studies ${ }^{50,51}$ have confirmed the presence of $\mathrm{CdBr}_{4}^{2-}$.

These structural informations are summarized in Table 1.

Table 1: Assumed structure of complexes $\mathrm{MX}_{n} \mathrm{~W}_{p}{ }^{2-n}(\mathrm{~W}=$ water molecule $)$

\begin{tabular}{lllll}
\hline Salt & $n=1$ & 2 & 3 & 4 \\
\hline $\mathrm{ZnCl}_{2}$ & $\mathrm{Zn}^{2+} \ldots \mathrm{Cl}^{-a}$ & $\mathrm{ZnCl}_{2} \mathrm{~W}_{4}^{0}$ & $\mathrm{ZnCl}_{3} \mathrm{~W}^{-}$ & $\mathrm{ZnCl}_{4}^{2-}$ \\
$\mathrm{ZnBr}_{2}$ & $\mathrm{Zn}^{2+} \ldots \mathrm{Br}^{-a}$ & $\mathrm{ZnBr}_{2} \mathrm{~W}_{4}^{0}$ & $\mathrm{ZnBr}_{3} \mathrm{~W}^{-}$ & $\mathrm{ZnBr}_{4}^{2-}$ \\
$\mathrm{ZnI}_{2}$ & $\mathrm{ZnIW}_{5}^{+}$ & $\mathrm{ZnI}_{2} \mathrm{~W}_{2}^{0}$ & $\mathrm{ZnI}_{3} W^{-}$ & $\mathrm{ZnI}_{4}^{2-}$ \\
$\mathrm{CdCl}_{2}$ & $\mathrm{CdClW}_{5}^{+}$ & $\mathrm{CdCl}_{2} \mathrm{~W}_{2}^{0}$ & $\mathrm{CdCl}_{3} \mathrm{~W}^{-}$ & $\mathrm{CdCl}_{4}^{2-}$ \\
$\mathrm{CdBr}_{2}$ & $?$ & $?$ & $?$ & $\mathrm{CdBr}_{4}^{2-}$ \\
$\mathrm{CdI}_{2}$ & $\mathrm{CdIW}_{5}^{+}$ & $?$ & $?$ & $\mathrm{CdI}_{4}^{2-}$ \\
\hline
\end{tabular}

${ }^{a}$ Ion pair.

In contrast with the structural features of the complexes, the formation constants of cadmium halides have been studied extensively. Results, and values adopted in 3 speciation softwares, for the complex formation constants, $\beta_{n}$, of zinc and cadmium halides are summarized in Table 2. Note that these values are for the thermodynamic constants, not apparent values of the $\beta_{n}$ 's at some finite concentration. They refer to infinite dilution of the salt. As it is well known, the $\beta_{n}$ values decrease in the series $\mathrm{Cl}-\mathrm{Br}-\mathrm{I}$ in the case of zinc complexes for every $n$, and they vary in the reverse order in the case of cadmium. One observes more consistency in the values for cadmium, for which complexes are more stable, than for those of zinc that are weaker and more scattered. The Davies equation has been often used to calculate constants to infinite dilution from low-ionic-strength measurements. ${ }^{52}$ This might have entailed some uncertainty on the $\beta_{n}$ values (maybe reflected in the values of the NIST database in some cases, see Table 2).

The case of $\mathrm{ZnI}_{2}$ is peculiar. It has been proposed that it behaves like a strong electrolyte below $0.8 \mathrm{~mol} \mathrm{~kg}{ }^{-1} .{ }^{53}$ At higher concentrations or in mixtures with iodide salts, the zinc(II) ion has been shown to form 4 types of complexes with iodide. ${ }^{36,47}$ However, it seems that no 
$\beta_{n}$ value has been determined and that only an upper bound for the first constant has been found (see Table 2).

\section{Modeling}

\section{Solution of complexation equilibria}

For a given salt concentration and a given set of $\beta_{n}$ values for $n$ going from 1 to 4 , the speciation (viz. the set of $C_{n}$ values) was solved by employing a Newton-Raphson method in 6 dimensions. The 6 equations to solve were the 4 equations for the equilibria (Eq. 2 for $n=1, \ldots, 4)$ in which the activity coefficients, $y_{n}$, were computed according to some model, and the 2 relations for the conservation of $\mathrm{M}$ and $\mathrm{X}$ elements. In the Newton-Raphson algorithm, the equations were written as a function of the variables $\left\{\ln C_{n}\right\}$ (not the $C_{n}$ 's) in order to avoid the appearance of negative values of the $C_{n}$ 's in the iterations. The inverse of the $6 \times 6$ Jacobian matrix was calculated analytically by using Maple, the symbolic

calculation software. At the first two lower concentrations, the system of equations was solved analytically by first neglecting deviations from ideality $\left(y_{n}=1\right.$ for any $n$ ), and then using this solution as a starting set in the iterations. At higher concentrations, the initial speciation was derived from an extrapolation of the sets of proportions of complexes obtained in the preceding two iterations.

The salt concentrations were computed from density data, which were fitted with a formula of the form,

$$
d=d_{0}+d_{1} m_{s}-d_{2} m_{s}^{3 / 2}
$$

with $m_{s}$ the salt molality. 
Table 2: Decimal logarithms of thermodynamic complex formation constants for zinc and cadmium halides.

\begin{tabular}{|c|c|c|c|c|c|}
\hline Salt & Source & $\beta_{1}{ }^{a}$ & $\beta_{2}{ }^{a}$ & $\beta_{3}{ }^{a}$ & $\beta_{4}{ }^{a}$ \\
\hline \multirow{9}{*}{$\mathrm{ZnCl}_{2}$} & $32 b$ & 0.5 & -1 & 0 & -1 \\
\hline & 29 & $0.43 \pm 0.20^{c}$ & $0.61 \pm 0.30^{c}$ & $0.53 \pm 0.30^{c}$ & $0.20 \pm 0.20^{c}$ \\
\hline & 33 & -0.1 & & & \\
\hline & 54 & 0.49 & 0.62 & 0.51 & 0.20 \\
\hline & 52 & $0.46 \pm 0.03$ & 0.6 & 0.5 & 0.2 \\
\hline & $\mathrm{NIST}^{22 d}$ & $0.46 \pm 3$ & & & \\
\hline & CHEAQS & $0.46^{e}$ & $0.62^{f}$ & $0.51^{f}$ & $0.20^{f}$ \\
\hline & PHREEQC & 0.43 & 0.45 & 0.50 & 0.20 \\
\hline & MINTEQ & 0.46 & 0.45 & 0.50 & 0.20 \\
\hline \multirow[t]{4}{*}{$\mathrm{ZnBr}_{2}$} & 55 & 0 & -0.15 & -0.45 & -0.97 \\
\hline & NIST $^{22}$ & -0.07 & & & \\
\hline & CHEAQS & $-0.07^{e}$ & & & \\
\hline & PHREEQC & -0.58 & -0.98 & & \\
\hline \multirow[t]{2}{*}{$\mathrm{ZnI}_{2}$} & 3,53 & $<-1$ & & & \\
\hline & CHEAQS & -2.04 & & & \\
\hline \multirow[t]{11}{*}{$\mathrm{CdCl}_{2}$} & $32 b$ & 1.95 & 2.5 & 2.35 & 1.65 \\
\hline & 56 & $2.00 \pm 0.02$ & $2.70 \pm 0.02$ & $2.11 \pm 0.04$ & \\
\hline & 57 & 2 & 2.6 & 2.7 & 3 \\
\hline & 58 & 2 & & & \\
\hline & 59,60 & $1.95 \pm 0.02$ & & & \\
\hline & 54 & 1.97 & 2.59 & 2.40 & 1.47 \\
\hline & 52 & $1.98 \pm 0.03$ & $2.6 \pm 0.1$ & $2.4 \pm 0.1$ & 1.7 \\
\hline & $\mathrm{NIST}^{22 d}$ & $1.98 \pm 3$ & $2.6 \pm 10$ & & \\
\hline & CHEAQS & $1.98^{e}$ & $2.6^{e}$ & 2.0 & $1.47^{f}$ \\
\hline & PHREEQC & 1.98 & 2.6 & 2.4 & \\
\hline & MINTEQ & 1.98 & 2.6 & & \\
\hline \multirow[t]{7}{*}{$\mathrm{CdBr}_{2}$} & 57 & 2.17 & 3.1 & 3.4 & 4 \\
\hline & 61 & 2.23 & 3 & 2.83 & 2.93 \\
\hline & 62 & $2.15 \pm 0.02$ & & & \\
\hline & 52 & $2.14 \pm 0.02$ & $3.0 \pm 0.1$ & $3.0 \pm 0.1$ & $2.9 \pm 0.2$ \\
\hline & $\mathrm{NIST}^{22 d}$ & $2.15 \pm 9$ & $3 \pm 0$ & $3 \pm 2$ & $2.9 \pm 0$ \\
\hline & CHEAQS & $2.15^{e}$ & $3^{e}$ & $3^{e}$ & $2.9^{e}$ \\
\hline & PHREEQC & 2.17 & 2.9 & & \\
\hline \multirow[t]{6}{*}{$\mathrm{CdI}_{2}$} & 57 & 2.42 & 3.4 & 5 & 6.15 \\
\hline & 27 & 2.28 & 3.92 & 5 & 6.1 \\
\hline & 63 & 2.42 & 3.15 & 5.05 & 5.89 \\
\hline & 52 & $2.28 \pm 0.10$ & $3.92 \pm 0.10$ & $5.0 \pm 0.1$ & $6.0 \pm 0.1$ \\
\hline & $\mathrm{NIST}^{22 d}$ & $2.28 \pm 10$ & $3.92 \pm 10$ & $5 \pm 1$ & $6 \pm 1$ \\
\hline & CHEAQS & $2.28^{e}$ & $3.92^{e}$ & $5^{e}$ & $6^{e}$ \\
\hline
\end{tabular}

${ }^{a}$ Decimal logarithm; ${ }^{b}$ Measurements at $17 \pm 3{ }^{\circ} \mathrm{C} ;{ }^{c}$ Uncertainties calculated from those on $x$ and $y\left(= \pm 0.05^{29}\right) ;{ }^{d}$ Values as given in the database; ${ }^{e}$ Taken from NIST database; ${ }^{22}$ ${ }^{f}$ Taken from ref. ${ }^{54}$ 


\section{Calculation of mean salt activity coefficient}

In this section we recall the relations permitting the calculation of the mean salt activity coefficient for a multiply self-complexing salt $\mathrm{MX}_{2}$.

As shown in Appendix G of ref., ${ }^{64}$ the chemical potentials of the elements $\mathrm{M}$ and $\mathrm{X}$ are equal to those of the corresponding free ions. Consequently, if these chemical potentials are expressed in terms of activities on molar scale (which is the case with CHEAQS), one has,

$$
\mu_{M} \equiv \mu_{M}^{(0)}+k_{B} T \ln \left(y_{M} C_{M}\right)=\mu_{M^{2+}} \equiv \mu_{M^{2+}}^{(0)}+k_{B} T \ln \left(y_{M^{2+}} C_{M^{2+}}\right)
$$

with $\mu_{i}$ the chemical potential of $i, \mu_{i}^{(0)}$ its standard value, $C_{M}$ the total concentration of $\mathrm{M}$, and $k_{B}$ is Boltzmann constant, and $T$ is temperature.

The standard chemical potentials $\mu_{M}^{(0)}$ and $\mu_{M^{2+}}^{(0)}$ being equal (as can be shown by considering Eq. 4 at infinite dilution where $y_{i}=1$ and the salt is completely dissociated), one gets from this relation that,

$$
y_{M}=y_{M^{2+}} \frac{C_{M^{2+}}}{C_{M}}=\frac{a_{M^{2+}}}{C_{M}}
$$

with $a_{M^{2+}}$ the activity of free metal cation on molarity scale, $a_{M^{2+}} \equiv y_{M^{2+}} C_{M^{2+}}$. A similar relation can be obtained likewise for the anion.

Consequently the mean salt activity coefficient, $y_{s}$, which is defined ${ }^{7}$ as, $y_{s}^{3} \equiv y_{M} y_{X}^{2}$, is given by,

$$
y_{s}^{3}=y_{M^{2+}}\left(y_{X^{-}}\right)^{2} \frac{C_{M^{2+}}}{C_{M}}\left(\frac{C_{X^{-}}}{C_{X}}\right)^{2}=a_{M^{2+}}\left(a_{X^{-}}\right)^{2} / 4 C_{s}^{3}
$$

in which subscript $s$ designates the salt $\mathrm{MX}_{2}$ and because $C_{M}=C_{s}$ and $C_{X}=2 C_{s}$.

The mean salt activity coefficient on molal scale is expressed as, ${ }^{7}$

$$
\gamma_{s}=y_{s} \frac{C_{s}}{m_{s} d_{0}}
$$


which, together with Eq. 6, leads to,

$$
\gamma_{s}=\frac{1}{m_{s} d_{0}}\left[\frac{a_{M^{2+}}\left(a_{X^{-}}\right)^{2}}{4}\right]^{1 / 3}
$$

with $a_{i} \equiv y_{i} C_{i}$.

Now, if activities are given on molal scale (which is supposed to be the case when using PHREEQC and MINTEQ), one may use the relation connecting the activities of a species $i$ on molal scale, $A_{i}$, and on molar scale $\left(a_{i}\right),{ }^{7}$

$$
a_{i}=A_{i} d_{0}
$$

By inserting this relation into Eq. 8 one obtains,

$$
\gamma_{s}=\frac{1}{m_{s}}\left(\frac{A_{M^{2+}} A_{X^{-}}{ }^{2}}{4}\right)^{1 / 3}
$$

\section{The Davies equation}

This equation was proposed by Davies in 1938 as an empirical extension of the Debye-Hückel limiting equation. ${ }^{23}$ Many softwares, such as, e.g., CHEAQS and PHREEQC, employ it for the calculation of the activity coefficients of the species at $25^{\circ} \mathrm{C}^{20,21}$ in the form,

$$
\ln y_{i} \simeq-0.5 z_{i}^{2}\left(\frac{\sqrt{I}}{1+\sqrt{I}}-a I\right)
$$

with $z_{i}$ is the valency of the ion, $I$ the ionic strength,

$$
I \equiv \frac{1}{2} \sum_{k} z_{k}^{2} C_{k}
$$

and $a$ a parameter that was taken as $a=0.2$ originally by Davies ${ }^{23}$ for a representation of activity coefficients of $2-1$ salts up to $I \simeq 0.1 \mathrm{~mol} \mathrm{~L}^{-1}$. 
Note that in most speciation softwares, the value $a=0.3$ is apparently used for solutions up to $I \simeq 1 \mathrm{~mol} \mathrm{~L}^{-1}$. With MINTEQ one can use this equation, or SIT which is supposed to be more accurate for more concentrated solutions. ${ }^{24}$

\section{MSA model}

A more refined theory derived from statistical mechanics is the primitive mean spherical approximation (MSA) applied to electrolytes. ${ }^{65}$

In this model an aqueous electrolyte solution is modeled as charged hard spheres (the ions) placed in a dielectric continuum (the water). The ions may have different diameters. As compared to the Debye-Hückel (DH) theory, the MSA accounts in a consistent way for the effect of the minimum distances of approach (excluded volume) between the ions in the cloud around an ion (not only with respect to a central ion as the DH theory does). ${ }^{34,66}$ Consequently, it better describes the distribution of ions about a given ion in concentrated solutions.

Similarly to the DH model, the MSA is a linearized theory which provides analytic expressions, and it is developed at the McMillan-Mayer level of solutions. ${ }^{67}$ At this level of description, the diameters of the ions may include a contribution from hydration. They should therefore be larger than (or equal to) their crystallographic diameters.

The expression of the activity coefficients of the ions within the MSA has been given in the literature. ${ }^{65,68,69}$ We recall now the main relations that will be used in this study.

Besides the electrostatic contribution, an additional contribution arising from volume exclusion is introduced in the expression of the activity coefficient of a species $i$ as,

$$
\ln y_{i}=\ln y_{i}^{H S}+\ln y_{i}^{e l}
$$

where the superscript 'HS' designates the hard sphere part corresponding to excluded volume effects, and 'el' designates the electrostatic contribution arising from Coulomb interactions 
between ions.

In this framework, it is this HS contribution which causes the activity coefficient of the salt to turn upwards beyond some concentration, after the initial drop at low concentration that is dominated by the electrostatic part (governed by Debye-Hückel law).

One has,

$$
\ln y_{i}^{H S}=-\ln x+\sigma_{i} F_{1}+\sigma_{i}^{2} F_{2}+\sigma_{i}^{3} F_{3}
$$

with $\sigma_{i}$ the diameter of $i, x$ the volume fraction of space not occupied by solute particles; $F_{1}, F_{2}$ and $F_{3}$ are functions given in ref., ${ }^{68}$ and

$$
\ln y_{i}^{e l}=-\frac{\beta e^{2}}{4 \pi \varepsilon \varepsilon_{0}}\left[\frac{\Gamma z_{i}^{2}}{1+\Gamma \sigma_{i}}+\eta \sigma_{i}\left(\frac{2 z_{i}-\eta \sigma_{i}^{2}}{1+\Gamma \sigma_{i}}+\frac{\eta \sigma_{i}^{2}}{3}\right)\right]
$$

in which $\beta \equiv 1 / k_{B} T, e$ is elementary charge, $\varepsilon_{0}$ is the permittivity of a vacuum, $\varepsilon$ is the relative permittivity of solution, and $\Gamma$ is the MSA screening parameter (the analog of the $\kappa$ screening parameter in Debye-Hückel theory) which satisfies the equation,

$$
4 \Gamma^{2}=\frac{\beta e^{2}}{\varepsilon \varepsilon_{0}} \sum_{i} \rho_{i}\left[\left(z_{i}-\eta \sigma_{i}^{2}\right) /\left(1+\Gamma \sigma_{i}\right)\right]^{2}
$$

and $\eta$ is a quantity that cancels out when the ions are of the same size. Its expression may be found in ref. ${ }^{68}$ Eq. 16 does not provide an analytic expression for $\Gamma$ in the general asymmetric case. Its value may be however easily determined numerically by using a simple iterative procedure, starting with the initial value, $\Gamma_{0}=\kappa / 2$.

\section{Results and discussion}

\section{Use of the Davies equation for strong electrolytes}

Before going specifically to the case of zinc and cadmium halides it will be useful to recall some basic results about the use of the Davies equation for strong electrolytes. So we 
first address the following question: how well does this equation describe deviations from ideality in such solutions ? For this purpose we examine here the case of a few 2-1 salts, namely $\mathrm{MgCl}_{2}$, and magnesium, zinc and cadmium perchlorates, which have been found experimentally to be completely dissociated in solution. ${ }^{49,70}$ The magnesium ion is interesting because its crystallographic radius is close to that of the zinc ion $\left(0.86\right.$ for $\mathrm{Mg}^{2+}$ vs. $0.88 \AA$ for $\mathrm{Zn}^{2+}$, as estimated by Shannon and Prewitt ${ }^{71}$ for a coordination number of 6 ).

The results are shown in Figure 1 in which the experimental mean salt activity coefficients on molal scale, $\gamma_{s}$, are compared with the predictions from the Davies equation, Eq. 11, with $a=0.1,0.2$ and 0.3 up to $I=1.6 \mathrm{~mol} \mathrm{~L}^{-1}$. Experimental values of $\gamma_{s}$ were obtained from a program developed at NBS, Gamphi, ${ }^{72}$ which gives recommended values for this quantity. In Figure 1, $\gamma_{s}$ is plotted against the ionic strength, $I=3 C_{s}$ for a $2-1$ salt. The salt concentration, $C_{s}$, was computed using the solution densities obtained from various sources. ${ }^{73-75}$

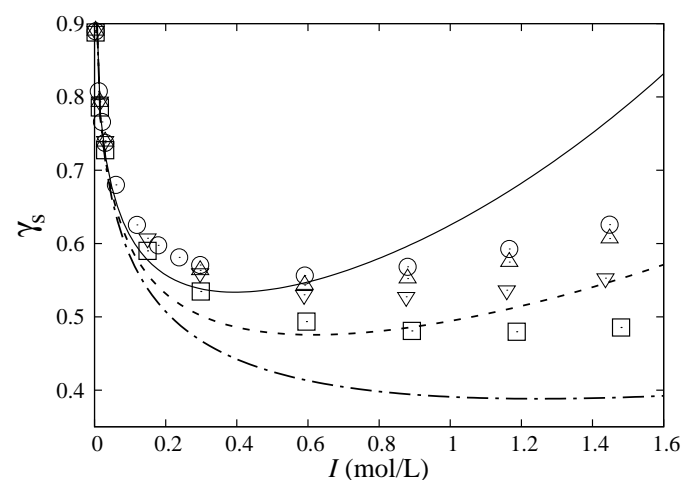

Figure 1: Mean salt activity coefficient as a function of ionic strength for $\mathrm{MgCl}_{2}(\square)$, $\mathrm{Mg}\left(\mathrm{ClO}_{4}\right)_{2}(\odot), \mathrm{Zn}\left(\mathrm{ClO}_{4}\right)_{2}(\triangle)$ and $\mathrm{Cd}\left(\mathrm{ClO}_{4}\right)_{2}(\nabla)$, and for 3 values of $a$ in the Davies equation: $a=0.1$ (dash-dotted line), $a=0.2$ (dashed line) and $a=0.3$ (solid line).

Figure 1 shows that the experimental data of the 4 salts are very similar up to $I \sim$ $0.3 \mathrm{M}$ and they diverge more and more above this value. The values for magnesium and zinc perchlorates are however very close in the whole range. The data for cadmium perchlorate lie below those for these salts. It is noticed that the Davies equation with $a=0.3$ is satisfactory 
up to $I=0.3 \mathrm{M}$, thus supporting the choice for the value of $a$ in the softwares. However, it does not predict correctly the activity coefficients of these 4 strong 2-1 electrolytes above $0.3 \mathrm{M}$, up to $1 \mathrm{M}$, for a unique value of $a$. In this range, the data for $\mathrm{MgCl}_{2}$ are better described for $a \sim 0.2$. In the case of the perchlorates of $\mathrm{Mg}, \mathrm{Zn}$ and $\mathrm{Cd}$, the representation is fair up to $I=0.6 \mathrm{M}$ for $a \sim 0.3$. At $I \simeq 0.9 \mathrm{M}\left(m=0.3 \mathrm{~mol} \mathrm{~kg}^{-1}\right)$, the Davies equation with $a=0.3$ overestimates the mean activity coefficient of $\mathrm{Mg}\left(\mathrm{ClO}_{4}\right)_{2}$ by ca. $5 \%$ and that of $\mathrm{MgCl}_{2}$ by ca. $25 \%$.

\section{Mean salt activity coefficient values computed using the Davies equation}

Now we present the results for the mean salt activity coefficient of zinc and cadmium halides when literature values for the complex formation constants are employed.

For a given concentration of the salt, the value of $\gamma_{s}$ was computed by equilibrating the total concentration of the cation among its various possible forms according to the method described in the section entitled "Solution of complexation equilibria". Equilibration was performed with the set of $\beta_{n}$ values employed in the software CHEAQS, which were taken from the NIST database ${ }^{22}$ or from the work of Turner et al. ${ }^{54}$ (see Table 2). It was checked that the speciation obtained from the present work was strictly identical to that found with CHEAQS for a given salt concentration. The Davies equation, Eq. 11, was used to calculate the individual activity coefficients of the species (for the free ions and the complexes). After completing this step, the value of $\gamma_{s}$ was found by using Eq. 8. Therefore, the same equation was used consistently to solve the complexation equilibria and to compute the value of $\gamma_{s}$.

For a given salt molality, the concentration was found from Eq. 3 together with the values of Table 3 for $d_{1}$ and $d_{2}$ that were found from least-square fits of experimental density data. ${ }^{74,76}$

In the case of zinc halides, recommended values for the experimental $\gamma_{s}$ were retrieved from the Gamphi program. ${ }^{72}$ Data for cadmium halides are not available from this source. 
Table 3: Values of parameters to be used in Eq. 3.

\begin{tabular}{lcccc}
\hline Salt & $\begin{array}{c}\text { Max. } m \\
\left(\mathrm{~mol} \mathrm{~kg}^{-1}\right)\end{array}$ & $\begin{array}{c}d_{1} \\
\left(\mathrm{~kg}^{2} /(\mathrm{mol} \mathrm{L})\right)\end{array}$ & $\begin{array}{c}10^{2} d_{2} \\
\left(\mathrm{~kg}^{5 / 2} /\left(\mathrm{mol}^{3 / 2} \mathrm{~L}\right)\right)\end{array}$ & Accuracy of fit \\
\hline $\mathrm{ZnCl}_{2}$ & 6 & 0.127067 & 1.92410 & $0.11 \%$ \\
$\mathrm{ZnBr}_{2}$ & 8.25 & 0.210528 & 3.15671 & $0.16 \%$ \\
$\mathrm{ZnI}_{2}$ & 13.8 & 0.290526 & 4.47943 & $0.44 \%$ \\
$\mathrm{CdCl}_{2}$ & 2.85 & 0.166494 & 1.70186 & $0.02 \%$ \\
$\mathrm{CdBr}_{2}$ & 2.45 & 0.253397 & 3.49709 & $0.16 \%$ \\
$\mathrm{CdI}_{2}$ & 2.2 & 0.324659 & 4.43186 & $0.16 \%$ \\
\hline
\end{tabular}

They were obtained from original publications for $\mathrm{CdCl}_{2},{ }^{26,77} \mathrm{CdBr}_{2}{ }^{62,77}$ and $\mathrm{CdI}_{2} \cdot{ }^{27,77}$

The experimental and calculated values for $\gamma_{s}$ are plotted in Figures 2-6 as a function of molality, together with the ionic strength calculated from the speciation and Eq. 12. The result for the particular case of $\mathrm{ZnI}_{2}$ is placed in the supporting information (SI) addendum. In these plots, the scale for $\gamma_{s}$ is on the left-hand side of the frame, and that for $I$ is on the right-hand side. Let us recall that $I=1 \mathrm{M}$ is generally regarded as the maximum value of $I$ up to which the Davies equation may be used in most speciation softwares. In Figure 2, the calculated $\gamma_{s}$ values for $\mathrm{ZnCl}_{2}$ are shown for 3 values of $a$ in Eq. 11, $a=0.1,0.2$ and 0.3.

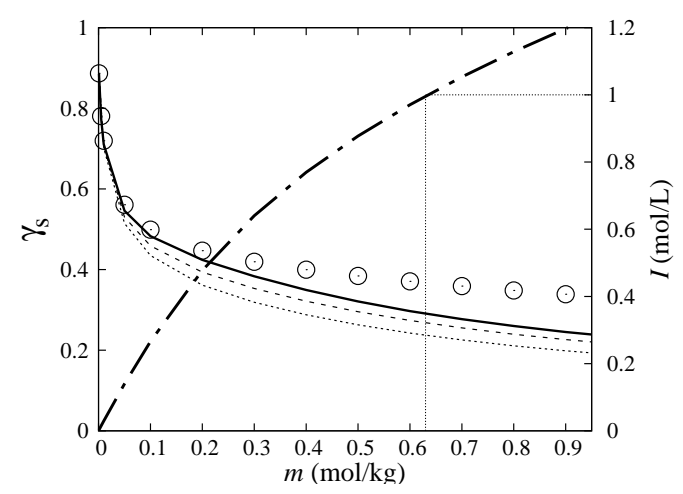

Figure 2: $\mathrm{ZnCl}_{2}$. Experimental and calculated values of mean salt activity coefficient, and ionic strength, as a function of molality, for 3 values of $a$ in the Davies equation: $a=0.3$ (solid line), $a=0.2$ (dashed line) and $a=0.1$ (dotted line). Dash-dotted line: ionic strength (right-hand scale). The molality at which $I=1 \mathrm{~mol} \mathrm{~L}^{-1}$ with $a=0.3$ is indicated with dotted lines.

The first striking remark about Figures 2-6 is that the calculated values for $\gamma_{s}$ are not 


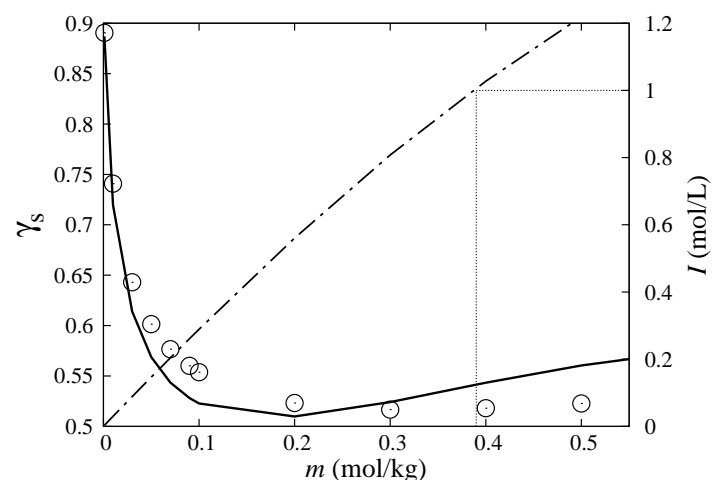

Figure 3: $\mathrm{ZnBr}_{2}$. Experimental and calculated values of mean salt activity coefficient, and ionic strength, as a function of molality, for $a=0.3$ (solid line). Dash-dotted line: ionic strength (right-hand scale). The molality at which $I=1 \mathrm{~mol} \mathrm{~L}^{-1}$ is indicated with dotted lines.

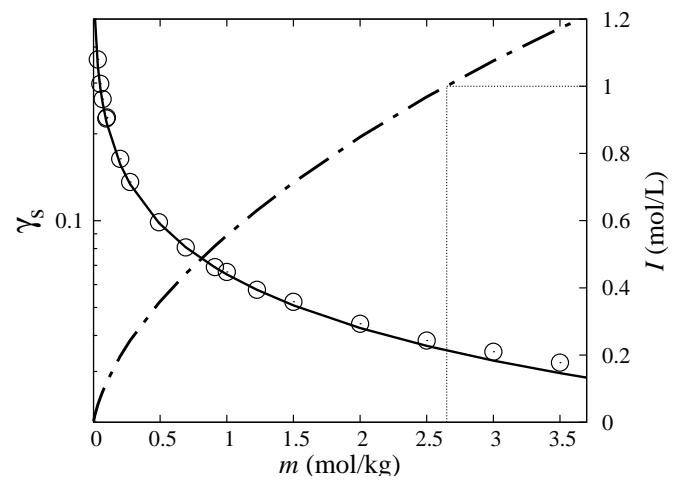

Figure 4: $\mathrm{CdCl}_{2}$. Same legend as for Figure 3. Log-scale for $\gamma_{s}$.

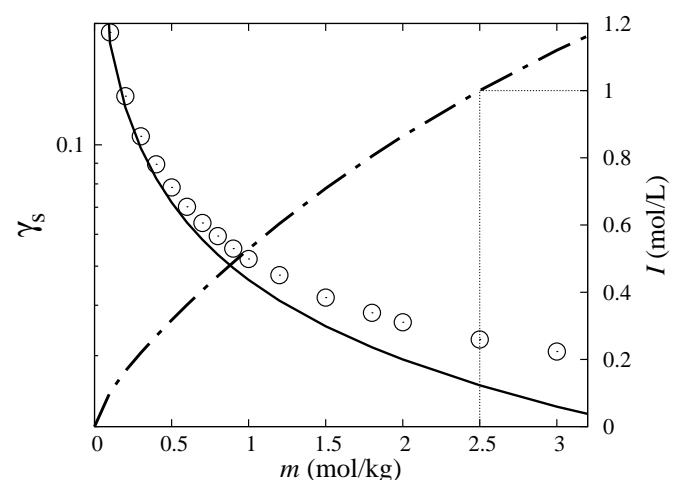

Figure 5: $\mathrm{CdBr}_{2}$. Same legend as for Figure 3. Log-scale for $\gamma_{s}$. 


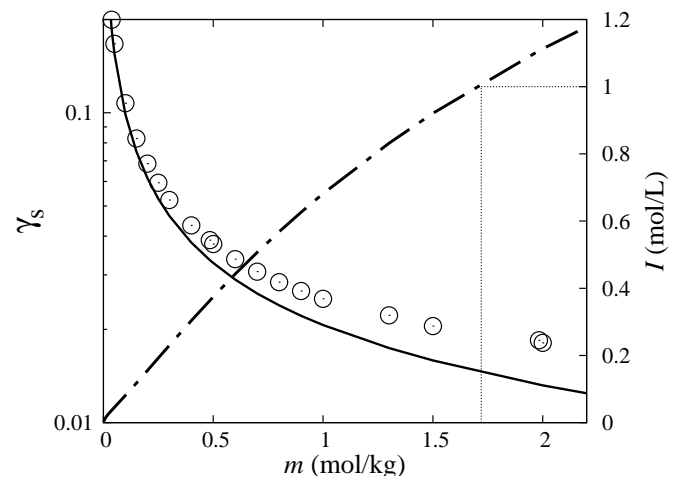

Figure 6: $\mathrm{CdI}_{2}$. Same legend as for Figure 3. Log-scale for $\gamma_{s}$.

in agreement with the experimental data in the case of $\mathrm{ZnCl}_{2}, \mathrm{CdBr}_{2}$ and $\mathrm{CdI}_{2}$, when ionic strength is typically larger than 0.3 or $0.4 \mathrm{M}$. For these 3 solutions, the calculated lines are significantly below the experimental points. In the case of $\mathrm{ZnCl}_{2}$, the use of SIT within MINTEQ yielded a similar result (see plot in Supplementary Information addendum). For this salt, in Figure 2, the deviation is larger for lower values of $a$. At $I=1 \mathrm{M}$ and for $a=0.3$, the relative deviation on $\gamma_{s}$ is of the order of $-23 \%$ for $\mathrm{ZnCl}_{2}$ and $\mathrm{CdBr}_{2}$, and of $-25 \%$ for $\mathrm{CdI}_{2}$. At low concentration, typically below $5 \times 10^{-3} \mathrm{~mol} \mathrm{~kg}^{-1}$, the calculated and experimental values agree very well as expected (experimental data satisfy the DebyeHückel limiting law), but the discrepancy increases gradually with concentration. Below 0.1 mol $\mathrm{kg}^{-1}$ the discrepancy is smaller than $8 \%$ in absolute value for all salts except $\mathrm{ZnI}_{2}$.

To the opposite, the results concerning solutions of $\mathrm{ZnBr}_{2}$ and $\mathrm{CdCl}_{2}$ are much better, with maximum deviations of $-5.6 \%$ and $-4.8 \%$ at $0.1 \mathrm{~mol} \mathrm{~kg}^{-1}$ for both salts, respectively. In the case of $\mathrm{ZnI}_{2}$ (see Supplementary Information), the maximum deviation is $\sim-11 \%$ at $0.08 \mathrm{~mol} \mathrm{~kg}^{-1}$.

The mixed results of this section lead to the following remarks and questions. The agreement between experimental and calculated values is fair at low concentration for all associating salts, and it is poor in the case of $\mathrm{ZnCl}_{2}, \mathrm{CdBr}_{2}$ and $\mathrm{CdI}_{2}$ in moderately concentrated solutions corresponding to $I \lesssim 1 \mathrm{~mol} \mathrm{~L}^{-1}$. Can this behavior be due to the use 
of the Davies equation, which has been shown to be of poor accuracy in that latter range (see Figure 1)? Would the agreement be better with the use of a better model ? Or do the discrepancies originate from unsuitable values of the complex formation constants?

In the next section it is proposed to address the first two questions by replacing the Davies equation with the MSA model presented in the section entitled "MSA model".

\section{Mean salt activity coefficient values computed using the MSA model}

\section{Case of strong 2-1 electrolytes}

First, data for the mean salt activity coefficient for the strong electrolytes considered in Figure 1 were represented within the MSA model. The fits were performed up to a molality of $1 \mathrm{~mol} \mathrm{~kg}^{-1}$ up to which the cation diameter, $\sigma_{0}$, and the solution permittivity, $\varepsilon$, may be regarded as constant, ${ }^{69}$ and there is no need for McMillan-Mayer to Lewis-Randall conversion of activity coefficients because it would be small at these concentrations. ${ }^{67}$ The relative permittivity of pure water was taken for $\varepsilon$ (viz., $\varepsilon=78.4$ ). Then, for a given salt, the only adjustable parameter was the cation diameter, $\sigma_{0}$, which is expected to be larger than the crystallographic value because of the effect of the hydration shell. For the anion, the Pauling diameter was used as in previous work ${ }^{69}$ because anions are known to be weakly hydrated. ${ }^{78}$ The perchlorate anion was assigned a diameter of $4.53 \AA$ as in previous studies within the MSA, ${ }^{69}$ which is in excellent accord with the thermochemical value of $4.52 \AA .79,80$

The MSA model provides therefore a rather simple description of activity coefficients in this type of solution. Moreover, the maximum molality of $1 \mathrm{~mol} \mathrm{~kg}^{-1}$ corresponds to an ionic strength $I \sim 3 \mathrm{M}$ for these strong electrolytes, which is 3 times larger than the upper limiting value with the Davies equation.

The results of the fits are gathered in Table 4 and they are plotted in Figure 7 . The average absolute relative deviations (AARD's) of fits are reported in the table.

Although the fits are not highly accurate, they are sufficient for the present approach, and the description is incomparably better than with the Davies equation (as can be seen in 
Table 4: Values of adjusted free cation diameter, $\sigma_{0}$, within the MSA in the case of strong 2-1 electrolytes up to $1 \mathrm{~mol} \mathrm{~kg}^{-1}$, together with the diameter taken for the anion, $\sigma_{X^{-}}$.

\begin{tabular}{lccc}
\hline Salt & $\sigma_{0}(\AA)$ & $\sigma_{X^{-}}(\AA)$ & AARD of fit \\
\hline $\mathrm{Mg}\left(\mathrm{ClO}_{4}\right)_{2}$ & 6.12 & 4.53 & $1.7 \%$ \\
$\mathrm{MgCl}_{2}$ & 5.79 & 3.62 & $2.0 \%$ \\
$\mathrm{Zn}\left(\mathrm{ClO}_{4}\right)_{2}$ & 6.03 & 4.53 & $2.4 \%$ \\
$\mathrm{Cd}\left(\mathrm{ClO}_{4}\right)_{2}$ & 5.59 & 4.53 & $2.6 \%$ \\
\hline
\end{tabular}

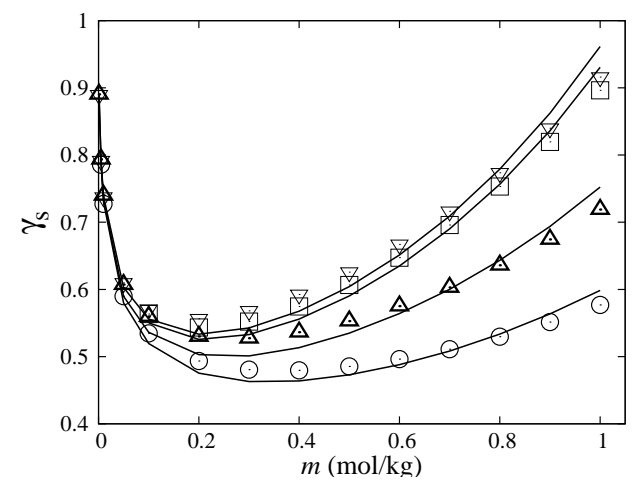

Figure 7: Fits of experimental mean salt activity coefficient data as a function of molality, using the MSA model. Symbols: $(\odot) \mathrm{MgCl}_{2} ;(\nabla) \mathrm{Mg}\left(\mathrm{ClO}_{4}\right)_{2} ;(\odot) \mathrm{Zn}\left(\mathrm{ClO}_{4}\right)_{2} ;(\triangle) \mathrm{Cd}\left(\mathrm{ClO}_{4}\right)_{2}$. Solid lines: optimum fits within MSA. 
Figures 1 and 7).

The adjusted diameters of $\mathrm{Mg}^{2+}, \mathrm{Zn}^{2+}$ and $\mathrm{Cd}^{2+}$ in Table 4 lie in the range 5.6-6.1 $\AA$. Overall, these $\sigma_{0}$ values are consistent with the picture of the cation being surrounded by one layer of water molecules (with a diameter for the water molecule of about $2.8 \AA^{81,82}$ ). The results for $\mathrm{Mg}^{2+}$ in the 2 salts, $\sigma_{0} \sim 5.8$ and $6.1 \AA$, are pretty consistent. These sizes are just a bit smaller than the diameter found earlier for the magnesium ion, namely $\sim 6.4 \AA$ at $1 \mathrm{M}$, with another version of the MSA model. ${ }^{69}$ The adjusted diameter of the $\mathrm{Cd}^{2+}$ ion is slightly smaller than that of $\mathrm{Zn}^{2+}$. This feature may be attributed to the greater size of the bare ion which, as a consequence, is less hydrated in solution. This trend has already been observed within the MSA for cations of the same column in the periodic table. ${ }^{69}$ The sizes for zinc(II) and cadmium(II) in the perchlorate salts, namely $6.03 \AA$ and $5.59 \AA$ respectively, were used hereafter for these cations.

\section{Sizes attributed to the complexes}

The last question is the sizes to assign to the various complexes.

First, available thermochemical diameters were used for the tetrahalo zinc complexes. ${ }^{80}$ In the case of the monochloro and monobromo zinc complexes, which are likely to be of ionic nature (see the section entitled "Structure of complexes and $\beta_{n}$ values"), their diameter was calculated as being that of a sphere having the same volume as the two ions constituting the ion pair.

For the other complexes of formula $\mathrm{MX}_{n} \mathrm{~W}_{p}{ }^{2-n}$ their diameter, $\sigma_{n}$, was estimated as follows. The total volume occupied by water molecules hydrating a free cation may be estimated as being, $v_{h}^{(0)} \equiv \pi / 6 \times\left(\sigma_{0}^{3}-\sigma_{M^{2+}}^{3}\right)$, with $\sigma_{M^{2+}}$ the diameter of the bare ion. The complex $\mathrm{MX}_{n} \mathrm{~W}_{p}{ }^{2-n}$ was viewed as a central metal ion possessing $n+p$ 'sites' to which $n$ anions $\mathrm{X}^{-}$and $p$ water molecules are bound. Then, it was assumed that the total volume of hydration water for such a complex is $v_{h}^{(n)} \simeq p /(n+p) \times v_{h}^{(0)}$ by considering that each site is hydrated as in the free ion and that no hydration water should be expected in the vicinity 
of anions belonging to the complex because of electrostatic effects. The volume of these hydrating water molecules was then added to the volume of the bare metal ion and that of the $n$ anions in the complex to obtain the total volume of the complex. Its diameter was finally taken to be that of a sphere having this total volume. Hence the following formula was used for the diameter of the complexes,

$$
\sigma_{n}^{3}=\frac{p}{n+p}\left(\sigma_{0}^{3}-\sigma_{M^{2+}}^{3}\right)+\sigma_{M^{2+}}^{3}+n \sigma_{X^{-}}^{3}
$$

in which $n+p(=4$ or 6$)$ is the coordination number of the metal ion obtained from Table 1.

As regards cadmium bromide and iodide complexes for $n=2$ and 3, it was supposed that they had the same structure as those of cadmium chloride (see Table 1).

The values of the $\sigma_{n}$ 's resulting from the use of Eq. 17 are gathered in Table 5.

Table 5: Values of the diameters $\sigma_{n}$ (in $\AA$ ) taken for the complexes (with $n$ the number of halide atoms in complex) according to Eq. 17 and for free anion $\mathrm{X}^{-}$.

\begin{tabular}{lcccccc}
\hline Salt & $\sigma_{0}$ & $\sigma_{1}$ & $\sigma_{2}$ & $\sigma_{3}$ & $\sigma_{4}$ & $\sigma_{X^{-}}$ \\
\hline $\mathrm{ZnCl}_{2}$ & 6.03 & 6.35 & 6.06 & 5.55 & 5.44 & 3.62 \\
$\mathrm{ZnBr}_{2}$ & 6.03 & 6.44 & 5.81 & 5.88 & 5.70 & 3.90 \\
$\mathrm{ZnI}_{2}$ & 6.03 & 6.33 & 6.60 & 6.46 & 6.18 & 4.32 \\
$\mathrm{CdCl}_{2}$ & 5.59 & 5.69 & 5.79 & 5.46 & 5.42 & 3.62 \\
$\mathrm{CdBr}_{2}$ & 5.59 & 5.80 & 6.00 & 5.81 & 5.88 & 3.90 \\
$\mathrm{CdI}_{2}$ & 5.59 & 6.01 & 6.38 & 6.39 & 6.62 & 4.32 \\
\hline
\end{tabular}

\section{Results for zinc and cadmium halides}

Then equilibrations in solutions of zinc and cadmium halides were performed using the MSA equations for the individual activity coefficients, Eqs. 13-15, by following the method described in the section entitled "Solution of complexation equilibria". The treatment was limited to salt concentrations such that the ionic strength was smaller than $3 \mathrm{M}$ as for the strong electrolytes of Figure 7. An additional condition was that the volume fraction occupied by the salt be smaller than 0.12 . This latter condition was imposed in order to take into 
account the effect of neutral dihalo compounds $\left(\mathrm{MX}_{2}\right)$ concentration. The upper value of 0.12 was the typical maximum volume fraction attained in the fits reported in Table 4 for the strong 2-1 electrolytes.

The results for $\gamma_{s}$ are presented in Figures 8-12. The plot in the case of $\mathrm{ZnI}_{2}$ is placed in the SI addendum. In order to take into account the uncertainty on the values of the diameters of the complexes, the calculations were performed for 2 extreme values, $\sigma_{n} \pm 0.2$ $\AA$, in which $\sigma_{n}$ is the value given in Table 5. Interestingly it was found numerically that the highest (resp. lowest) values of $\gamma_{s}$ are obtained for the highest (resp. lowest) values for all of the $\sigma_{n}$ 's at the same time. Consequently, in Figures 8-12, the lower and upper plots of $\gamma_{s}$ give the extreme values of this quantity when the diameters are in the range $\sigma_{n} \pm 0.2 \AA$.

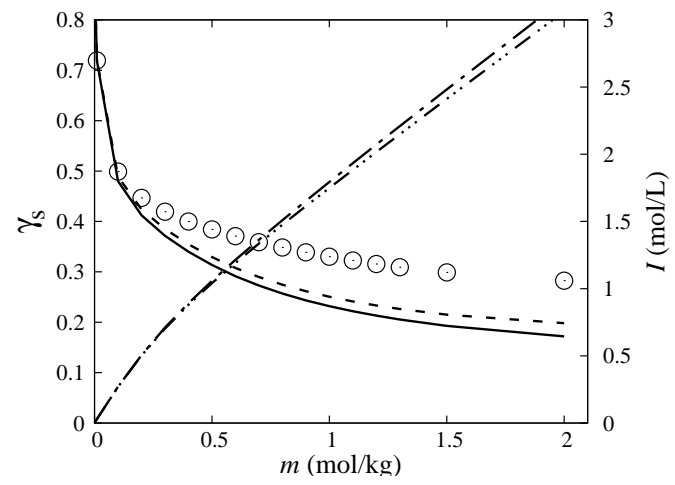

Figure 8: $\mathrm{ZnCl}_{2}$. Experimental $(\odot)$ and calculated MSA values of mean salt activity coefficient, and ionic strength, as a function of molality. Solid line: MSA result for minimum values of diameters; dotted line: idem for maximum values of diameters (see text). Dash-dot line: ionic strength (right-hand scale) for the minimum values of all diameters; dash-triple-dot line: ionic strength for the maximum values of all diameters.

The following comments may be made about these results. In the case of the $\mathrm{ZnCl}_{2}$ solution, the MSA prediction is appreciably below the experimental data, as has been observed in Figure 2 with the Davies equation. Nevertheless the discrepancy is smaller with the MSA. It is now $\sim-16 \%$ at $I=1 \mathrm{M}$ instead of $-23 \%$ with the Davies equation, but it is $\sim-35 \%$ at 2 mol kg${ }^{-1}$ at which $I \sim 3 \mathrm{M}$. The deviation between the MSA calculation and the experimental data in the case of $\mathrm{ZnBr}_{2}$ (Figure 3) is a bit worse than with the Davies equation. 


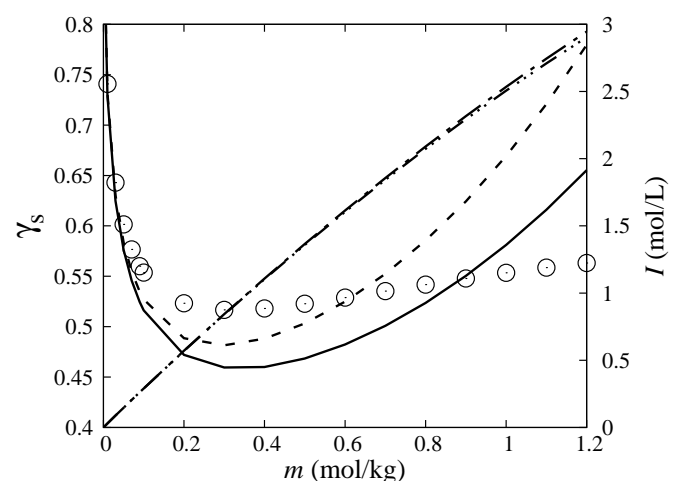

Figure 9: $\mathrm{ZnBr}_{2}$. MSA result. Same legend as for Figure 8.

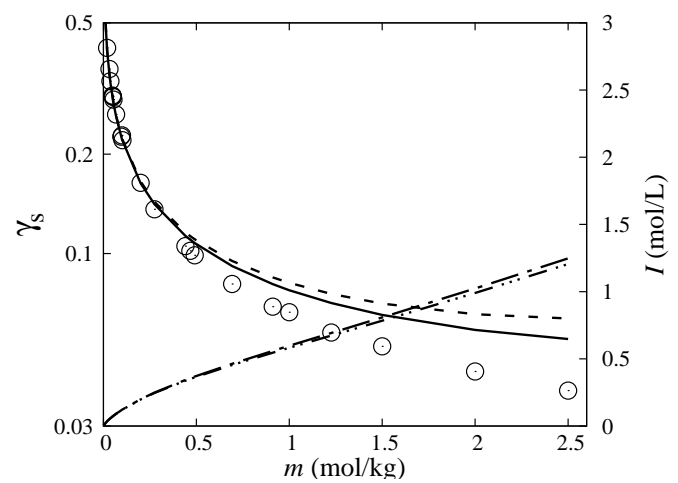

Figure 10: $\mathrm{CdCl}_{2}$. MSA result. Same legend as for Figure 8. Log-scale for $\gamma_{s}$.

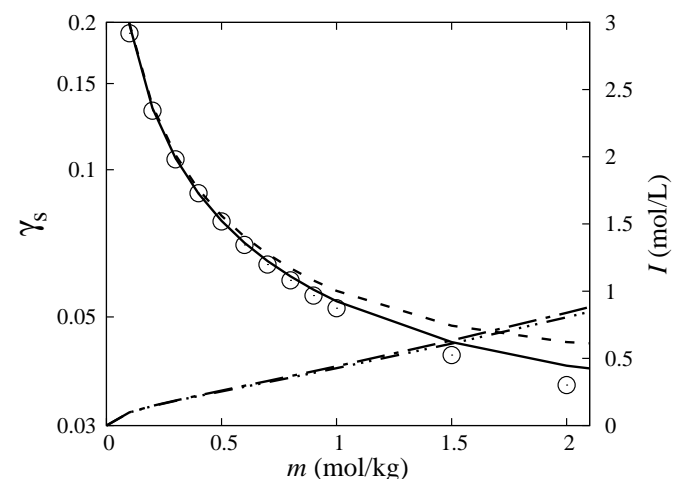

Figure 11: $\mathrm{CdBr}_{2}$. MSA result. Same legend as for Figure 8. Log-scale for $\gamma_{s}$. 


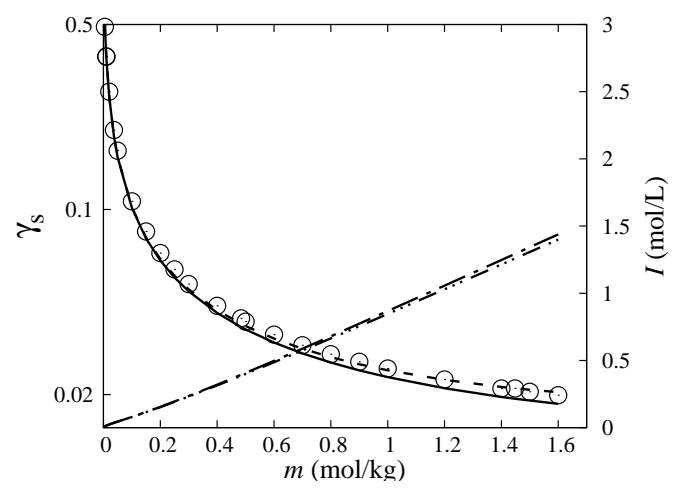

Figure 12: $\mathrm{CdI}_{2}$. MSA result. Same legend as for Figure 8. Log-scale for $\gamma_{s}$.

The average MSA curve is below the data up to $\sim 0.8 \mathrm{~mol} \mathrm{~kg}^{-1}$ and then it deviates more and more to the upside, reaching an average deviation of the order of $27 \%$ at $1.2 \mathrm{~mol} \mathrm{~kg}^{-1}$. The agreement is a bit better in the case of $\mathrm{ZnI}_{2}$ (see Figure $\mathrm{S} 2$ in $\mathrm{SI}$ ) but the discrepancy is notable between 0.1 and $0.8 \mathrm{~mol} \mathrm{~kg}^{-1}$ (a range in which it had yet been regarded as a strong electrolyte $\left.^{53}\right)$.

The description of cadmium halide solutions was done for ionic strengths lower than $3 \mathrm{M}$ (up to $1 \mathrm{M}$ or $1.5 \mathrm{M}$ ) because of the condition on solute volume fraction $(\leq 0.12)$ which contained a high proportion of neutral $\mathrm{CdX}_{2}$ complex. However, overall, the representations could be done up to molalities higher than in the case of zinc salts. One notices that the descriptions are of decreasing quality in the series $\mathrm{CdI}_{2}>\mathrm{CdBr}_{2}>\mathrm{CdCl}_{2}$. This is in contrast with the results from using the Davies equation in which $\mathrm{CdCl}_{2}$ gave the best agreement.

One notices also that the MSA plots exhibit a rather low sensitivity to the variation of the sizes of the species, except in the case of the weakly associated salts, $\mathrm{ZnBr}_{2}$ and $\mathrm{ZnI}_{2}$.

Against this backdrop it was attempted to determine alternative complexity constants that provide agreement of MSA results with experimental data. This is the purpose of the next section. 


\section{Determination of complexity constants within the MSA framework.}

A global search for a set of $\beta_{n}$ values that minimized the average absolute relative deviation (AARD) for $\gamma_{s}$ w.r.t. experimental data was undertaken within the MSA model. This global minimization procedure was initially carried out on wide intervals for the $\beta_{n}$ 's, namely in the range $\beta_{n}^{(0)} / 100$ to $100 \times \beta_{n}^{(0)}$ (in which $\beta_{n}^{(0)}$ is the value taken in CHEAQS). Then the procedure was repeated on progressively narrower intervals until the complexity constants were determined with sufficient accuracy. In this procedure the diameters of Table 5 were employed to calculate the values of $\gamma_{s}$.

The results are shown in Table 6 . No value is given in the case of $\mathrm{ZnI}_{2}$ because it was not possible to obtain a satisfactory fit for this salt. Actually it exhibits an unexpected behavior in which the experimental data are above the MSA result without association at all. The case of this solution will be reserved for subsequent examination.

Table 6: Decimal logarithms of the values of the complex formation constants, $\log _{10} \beta_{n}$.

\begin{tabular}{lcccccc}
\hline Salt & $\begin{array}{c}\text { max. } m \\
\left(\mathrm{~mol} \mathrm{~kg}^{-1}\right)\end{array}$ & $\beta_{1}$ & $\beta_{2}$ & $\beta_{3}$ & $\beta_{4}$ & AARD on $\gamma_{s}$ \\
\hline $\mathrm{ZnCl}_{2}$ & 2 & 0.15 & 0.27 & 0.30 & -2.3 & $0.15 \%$ \\
$\mathrm{ZnBr}_{2}$ & 1.2 & $-\infty^{a}$ & $-\infty^{a}$ & -0.85 & -2.1 & $2.1 \%$ \\
$\mathrm{CdCl}_{2}$ & 2.5 & 1.94 & 2.5 & 2.5 & 3 & $1.7 \%$ \\
$\mathrm{CdBr}_{2}$ & 2 & 2.27 & 2.34 & 2.92 & 3.60 & $0.8 \%$ \\
$\mathrm{CdI}_{2}$ & 1.6 & 2.33 & 3.87 & 4.02 & 6.0 & $0.5 \%$ \\
\hline \multicolumn{6}{c}{${ }^{a} \beta_{1}=\beta_{2}=0}$.
\end{tabular}

In the adjustments of Table 6 the best agreement for $\gamma_{s}$ with experiment is obtained in the case of $\mathrm{ZnCl}_{2}$, with values that are approximately within the uncertainty range of ref., ${ }^{29}$ except for $\beta_{4}$ which is much smaller. We note that these values differ significantly from those used in the softwares. In the case of $\mathrm{ZnBr}_{2}$ one gets $\beta_{1}=\beta_{2}=0$, which disagrees with the value proposed in NIST database $\left(\log _{10} \beta_{1}=-0.07\right)$. As seen in Table 2, PHREEQC employs alternative values $\left(\log _{10} \beta_{1}=-0.58\right.$ and $\left.\log _{10} \beta_{2}=-0.98\right)$. We are not aware of the source of these $\beta_{1}$ and $\beta_{2}$ values taken in PHREEQC.

In the case of $\mathrm{CdCl}_{2}$ the first three constants are in keeping with the values presented 
in Table 2 and the last one coincides with that found in ref. ${ }^{57}$ However, as compared to the values taken in Figure 10, the $\beta_{3}$ and $\beta_{4}$ values of Table 6 are appreciably higher, which sends the MSA prediction lower now in Figure 10 so that it coincides with experimental data. Overall, the results for $\mathrm{CdBr}_{2}$ are consistent with the literature values of Table 2. A comparison with the values used for Figure 11 (in which some discrepancy was observed) shows that $\beta_{2}$ is smaller and $\beta_{4}$ is somewhat larger. In the case of $\mathrm{CdI}_{2}$, the literature values of the $\beta_{n}$ 's already gave a good description of experimental data in Figure 12. The new fit lowers the value of the third constant to $\beta_{3} \sim 4$ from a value of 5 in Table 2 . The other $\beta_{n}$ values are essentially unchanged as compared to those of Table 2.

In these fits, 4 complexity constants have been adjusted. Those for cadmium complexes, especially the constants corresponding to the lower values of $n$, are in better agreement with literature values than the constants for $\mathrm{ZnCl}_{2}$ because cadmium complexes are significantly stronger than those of zinc. A high value of $\beta_{1}$ governs the behavior of the salt activity coefficient at low concentration. As a consequence any model or formula valid at low concentration, i.e. satisfying the DH limiting law, will give a correct value for this complexity constant. The effect of constants corresponding to higher stoichiometries comes progressively into play when the concentration is increased.

In contrast, the $\beta_{n}$ values of Table 6 for zinc chloride are consequently still uncertain. They will need to be confirmed, or refined, by considering ternary mixtures of $\mathrm{ZnCl}_{2}$ with another salt with common anion, which will constrain the adjustments more strongly. In the case of the cadmium complexes this will produce more complexes of higher stoichiometry and thus more accuracy on the corresponding complexity constants.

Finally Figure 13 shows the results for the proportions of free zinc cation, $p_{0} \equiv C_{0} / C_{Z n}$ (with $C_{Z n}=C_{s}$ the total concentration of zinc), and first (ionic) complex, $p_{1} \equiv C_{1} / C_{Z n}$, in zinc chloride solutions, as obtained $(i)$ using the Davies equation with the $\beta_{n}$ values taken by CHEAQS (see Table 2) and (ii) using the MSA equation with the $\beta_{n}$ values of Table 6 . Description $(i i)$ within the MSA predicts a concentration of free zinc ion that is much higher 
than with description $(i)\left(\sim 68 \%\right.$ larger at $\left.0.7 \mathrm{~mol} \mathrm{~kg}^{-1}\right)$. On the other hand $p_{1}$ calculated from procedure $(i)$ is more than twice the value derived from $(i i)$ in the range of 0.5 to 0.7 mol kg${ }^{-1}$. The results for the other complexes are displayed in the SI addendum. The curves for $p_{3}$ displayed in Figure S4 (in the SI addendum) are quite similar. On the other hand, those for $p_{2}$, and especially $p_{4}$, are very different. As it could be clearly expected in view of the different values of the complexity constants used in the two procedures, the speciation differs strongly in the two cases $(i)$ and $(i i)$.

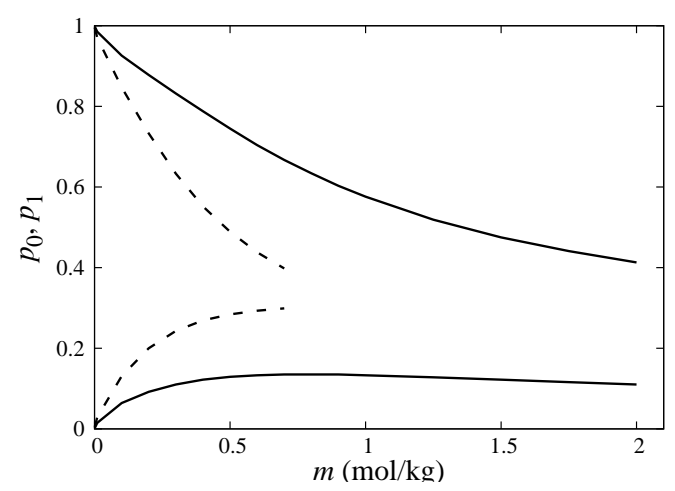

Figure 13: Proportions of free zinc cation (upper lines), $p_{0}$, and of ion pair $\mathrm{Zn}^{2+} \ldots \mathrm{Cl}^{-}$ (bottom lines), $p_{1}$, in $\mathrm{ZnCl}_{2}$ solutions as a function of molality. Solid lines= MSA result with $\beta_{n}$ values of Table 6; dashed lines= result using the Davies equation with the $\beta_{n}$ values taken in CHEAQS (Table 2) for $I<1 \mathrm{M}\left(m<0.7 \mathrm{~mol} \mathrm{~kg}^{-1}\right)$.

\section{Conclusion}

It has been shown in this work that if the speciation is calculated using the Davies equation to estimate deviations from ideality together with literature values for the complexity constants, then a thermodynamic inconsistency may appear in moderately concentrated solutions. Namely the mean salt activity coefficient is found to differ significantly from the experimental values in some cases. This discrepancy reveals the existence of a shortcoming in the description. It originates in part from the use of the Davies equation, which provides a poor representation of activity coefficients and, presumably, from the fact that some 
commonly admitted values for the complex formation constants are not sufficiently accurate.

Consequently, it might be desirable to use a better model to express deviations from ideality. Here, the MSA model has been proposed for this purpose, and revised complex formation constants have been determined.

However, it is clear that these values are provisional ones in this framework because they have been obtained in the case of pure binary solutions. This is probably especially true in the case of zinc solutions which form weak complexes. These complexity constants will have to be confirmed in subsequent work by examining the case of ternary solutions with common anion. The introduction of an additional 'degree of freedom' (through the decoupling of metal and anion concentrations) will bring more constraint on the fits of the complexity constants, and allow a determination of the latter with greater accuracy.

The case of other metal complexes will be considered in future work. At the level of modeling, an alternative way of accounting for ionic complexes will be examined. This could be done by employing another version of the MSA that includes association explicitly, namely the binding MSA (BiMSA) ${ }^{83,84}$ or equivalently the associative MSA (AMSA). ${ }^{85}$

\section{ASSOCIATED CONTENT Supporting Information}

The Supporting Information is available free of charge on the ACS Publications website at DOI:...

Mean salt activity coefficient values computed using the Davies equation (for $\mathrm{ZnI}_{2}$ ), the SIT (for $\mathrm{ZnCl}_{2}$ ) and the MSA model (for $\mathrm{ZnI}_{2}$ ); Speciation in solutions of zinc chloride: Proportion of complexes $\mathrm{ZnCl}_{2}, \mathrm{ZnCl}_{3}^{-}$and $\mathrm{ZnCl}_{4}^{2-}$, obtained from the Davies equation with literature values for the $\beta_{n}$ 's, and from the MSA with revised values. 


\section{References}

(1) Brezonik, P.; Arnold, W. Water chemistry: an introduction to the chemistry of natural and engineered aquatic systems; Oxford University Press, 2011.

(2) Cotton, F. A.; Wilkinson, G. Advanced Inorganic Chemistry, 5th ed.; Wiley New York, 1988.

(3) Sillen, L. G.; Martell, A. E. Stability constants of metal-ion complexes. Section 1; London Chemical Society, 1964.

(4) Ohtaki, H.; Radnai, T. Structure and dynamics of hydrated ions. Chem. Rev. 1993, 93, 1157-1204.

(5) Baes, C. F.; Mesmer, R. E. The hydrolysis of cations; Wiley, 1976.

(6) Holovko, M.; Druchok, M.; Bryk, T. A molecular dynamics modelling of cation hydrolysis effects. J. Electroanal. Chem. 2005, 582, 50-56.

(7) Robinson, R.; Stokes, R. Electrolyte Solutions; Butterworths, 1968.

(8) Simonin, J.-P.; Ramos, J. M.; Torres-Arenas, J. Diffusion coupling in multiply associating electrolyte solutions. J. Mol. Liq. 2016, 215, $69-76$.

(9) Ruaya, J.; Seward, T. The stability of chlorozinc(II) complexes in hydrothermal solutions up to $350^{\circ} \mathrm{C}$. Geochim. Cosmochim. Acta 1986, 50, 651-661.

(10) Cernochova, K.; Mathur, J.; Choppin, G. R. Chemical speciation of Am, Cm and Eu with EDTA at high ionic strength: thermodynamics and laser fluorescence spectroscopy studies. Radiochim. Acta 2005, 93, 733-739.

(11) Kola, H.; Wilkinson, K. J. Cadmium Uptake by a Green Alga Can Be Predicted by Equilibrium Modelling. Environ. Sci. Technol. 2005, 39, 3040-3047. 
(12) Markich, S. J.; Brown, P. L.; Jeffree, R. A.; Lim, R. P. The Effects of pH and Dissolved Organic Carbon on the Toxicity of Cadmium and Copper to a Freshwater Bivalve: Further Support for the Extended Free Ion Activity Model. Arch. Environ. Contam. Toxicol. 2003, 45, 479-491.

(13) VanBriesen, J. M.; Small, M.; Weber, C.; Wilson, J. Modelling of Pollutants in Complex Environmental Systems; ILM Publications, 2010; Vol. 2; Chapter Modelling Chemical Speciation: Thermodynamics, Kinetics and Uncertainty, pp 133-149.

(14) Galceran, J.; Huidobro, C.; Companys, E.; Alberti, G. AGNES: A technique for determining the concentration of free metal ions. The case of $\mathrm{Zn}(\mathrm{II})$ in coastal Mediterranean seawater. Talanta 2007, 71, 1795-1803.

(15) Bayen, S.; Worms, I.; Parthasarathy, N.; Wilkinson, K.; Buffle, J. Cadmium bioavailability and speciation using the permeation liquid membrane. Anal. Chim. Acta 2006, $575,267-273$.

(16) MINTEQ, software developed in the U.S. (MINTEQA2) and in Sweden (Visual MINTEQ). https://vminteq.lwr.kth.se/.

(17) CHESS, software developed in France. http://chess.geosciences.mines-paristech.fr/.

(18) SPECIATION, version 3.2, The IUPAC Stability Constants Database, SC-Database and Mini-SCDatabase. 2002; Academic Software, UK, http://www.acadsoft.co.uk.

(19) MINEQL+, software developed in the US. http://www.mineql.com.

(20) PHREEQC Interactive version 3, free software developed at US Geological Survey (USGS). https://wwwbrr.cr.usgs.gov/projects/GWC_coupled/phreeqc/.

(21) Verweij, W. CHEAQS, software developed in the Netherlands. http://www.cheaqs.eu/.

(22) Smith, R.; Martell, A.; Motekaitis, R. NIST Database 46 Version 8.0, Critically Selected Stability Constants of Metal Complexes. 2004; http://www.nist.gov/srd/nist46.cfm. 
(23) Davies, C. W. The extent of dissociation of salts in water. Part VIII. An equation for the mean ionic activity coefficient of an electrolyte in water, and a revision of the dissociation constants of some sulphates. J. Chem. Soc. 1938, 2093-2098.

(24) Guggenheim, E. The specific thermodynamic properties of aqueous solutions of strong electrolytes. Phil. Mag. 1935, 19, 588-643.

(25) Dyrssen, D.; Wedborg, M. Equilibrium calculations of the speciation of elements in seawater. The sea 1974, 5, 181-195.

(26) Reilly, P.; Stokes, R. The activity coefficients of cadmium chloride in water and sodium chloride solution at $25^{\circ}$. Aust. J. Chem. 1970, 23, 1397-1406.

(27) Bates, R. G.; Vosburgh, W. C. Equilibria in Cadmium Iodide Solutions. J. Am. Chem. Soc. 1938, 60, 137-141.

(28) Short, E.; Morris, D. Zinc chloride and zinc bromide complexes I. Cation exchange studies with zinc-65 tracer. J. Inorg. Nucl. Chem. 1961, 18, $192-198$.

(29) Marcus, Y.; Maydan, D. Anion exchange of metal complexes. VIII. The effect of the secondary cation. The zinc-chloride system. J. Phys. Chem. 1963, 67, 979-983.

(30) Kivalo, P.; Luoto, R. Polarographic determination of stability constants using the indicator method. Suom. Kemistil. B 1957, 30, 163-167.

(31) Morris, D.; Anderson, D.; Waters, S.; Reed, G. Zinc chloride and zinc bromide complexes IV. Stability constants. Electrochim. Acta 1969, 14, $643-650$.

(32) Marcus, Y.; Coryell, C. The anion exchange of metal complexes. I. Theory. Bull. Res. Council Isr. A 1959, 8, 1-16.

(33) Libuś, Z.; Tiałowska, H. Stability and nature of complexes of the type $\mathrm{MCl}^{+}$in aqueous solution (M=Mn, Co, Ni, and Zn). J. Solution Chem. 1975, 4, 1011-1022. 
(34) Blum, L. Primitive electrolytes in the mean spherical approximation. Theoretical Chemistry: Advances and Perspectives 1980, 5, 1-66.

(35) Anderson, A. J.; Mayanovic, R. A.; Bajt, S. A microbeam XAFS study of aqueous chlorozinc complexing to 430 degrees $\mathrm{C}$ in fluid inclusions from the Knaumuehle granitic pegmatite, Saxonian granulite massif, Germany. Canadian Mineralogist 1998, 36, 511524.

(36) Delwaulle, M. Etude au moyen de l'effet Raman de la constitution des solutions d'iodure, de bromure et de chlorure de zinc dissous seuls ou en présence d'ions halogènes - Mise en évidence des molécules non ionisées $\mathrm{ZnX}_{2}$ et des ions $\mathrm{ZnX}_{4}^{--}$. C. $R$. Acad. Sci. (France) 1955, 240, 2132-2134.

(37) Morris, D.; Short, E. L.; Waters, D. Zinc chloride and zinc bromide complexes - III Structures of species in solution. J. Inorg. Nucl. Chem. 1963, 25, 975-983.

(38) Kaatze, U.; Lönnecke, V.; Pottel, R. Dielectric spectroscopy on aqueous solutions of zinc(II) chloride. Evidence of ion complexes. J. Phys. Chem. 1987, 91, 2206-2211.

(39) Maeda, M.; Ito, T.; Hori, M.; Johansson, G. The structure of zinc chloride complexes in aqueous solution. Z. Naturforsch. A 1996, 51, 63-70.

(40) Tamura, K. Ultrasonic absorption studies of the complex formation of zinc(II) halides in aqueous solution. J. Phys. Chem. 1977, 81, 820-826.

(41) Salmon, P. Hydration of complexed chloride ions in aqueous zinc(II) chloride solution. J. Phys. Chem. 1989, 93, 1182-1184.

(42) Quicksall, C.; Spiro, T. Raman spectra of terachlorozincates and the structure of $\mathrm{ZnCl}_{4}^{2-}$. Inorg. Chem. 1966, 5, 2232-2233.

(43) Harris, D. J.; Brodholt, J. P.; Sherman, D. M. Zinc Complexation in Hydrothermal 
Chloride Brines: Results from ab Initio Molecular Dynamics Calculations. J. Phys. Chem. A 2003, 107, 1050-1054.

(44) Parchment, O. G.; Vincent, M. A.; Hillier, I. H. Speciation in aqueous zinc chloride. An ab initio hybrid microsolvation/continuum approach. J. Phys. Chem. 1996, 100, 9689-9693.

(45) Pye, C. C.; Corbeil, C. R.; Rudolph, W. W. An ab initio investigation of zinc chloro complexes. Phys. Chem. Chem. Phys. 2006, 8, 5428-5436.

(46) Yongyai, Y.; Kokpol, S.; Rode, B. M. Microstructure and species distribution of aqueous zinc chloride solutions: results from Monte Carlo simulations. J. Chem. Soc. Faraday Trans. 1992, 88, 1537-1540.

(47) Wakita, H.; Johansson, G.; Sandström, M.; Goggin, P. L.; Ohtaki, H. Structure determination of zinc iodide complexes formed in aqueous solution. J. Solution Chem. 1991, 20, 643-668.

(48) Bazarkina, E. F.; Pokrovski, G. S.; Zotov, A. V.; Hazemann, J.-L. Structure and stability of cadmium chloride complexes in hydrothermal fluids. Chem. Geol. 2010, 276, $1-17$.

(49) Ohtaki, H.; Johansson, G. X-ray diffraction studies on the structures of cadmium iodide complexes in water and in DMSO solutions. Pure Applied Chem. 1981, 53, 1357-1364.

(50) Macklin, J. W.; Plane, R. A. Raman study of stepwise formation of bromide complexes of zinc, cadmium, and mercury in aqueous solution. Inorg. Chem. 1970, 9, 821-827.

(51) Rolfe, J.; Sheppard, D.; Woodward, L. Raman spectra of complex cadmium and mercuric halide anions in solution. Trans. Faraday Soc. 1954, 50, 1275-1283.

(52) Martell, A. E.; Smith, R. M. Critical Stability Constants: First Supplement; Springer Science \& Business Media, 2013; Vol. 5. 
(53) Bates, R. G. The Thermodynamics of Bi-univalent Electrolytes. III. Zinc Iodide in Aqueous Solution. J. Am. Chem. Soc. 1938, 60, 2983-2990.

(54) Turner, D.; Whitfield, M.; Dickson, A. The equilibrium speciation of dissolved components in freshwater and sea water at $25^{\circ} \mathrm{C}$ and 1 atm pressure. Geochim. Cosmochim. Acta 1981, 45, 855-881.

(55) Horne, R. A.; Holm, R. H.; Meyers, M. D. The Adsorption of Zinc(II) on Anionexchange Resins. III. The Adsorption from Bromide, Fluoride, Cyanide, Oxalate, Acetate, Nitrate, Phosphate, Sulfate and Alkaline Media, the Perchlorate Eflect and Adsorption from Mixed Solvent Media. J. Phys. Chem. 1957, 61, 1661-1665.

(56) Vanderzee, C. E.; Dawson Jr, H. J. The Stability Constants of Cadmium Chloride Complexes: Variation with Temperature and Ionic Strength. J. Am. Chem. Soc. 1953, $75,5659-5663$.

(57) Riley, H. L.; Gallafent, V. A potentiometric investigation of electrolytic dissociation. Part I. Cadmium halides. J. Chem. Soc. 1932, 514-523.

(58) Righellato, E. C.; Davies, C. W. The extent of dissociation of salts in water. Part II. Uni-bivalent salts. Trans. Faraday Soc. 1930, 26, 592-600.

(59) Harned, H. S.; Fitzgerald, M. E. The Thermodynamics of Cadmium Chloride in Aqueous Solution from Electromotive Force Measurements. J. Am. Chem. Soc. 1936, 58, $2624-2629$.

(60) Treumann, W. B.; Ferris, L. M. The Simultaneous Evaluation of the Stability Constant for the $\mathrm{CdCl}^{+}$Ion and the Standard State Potential of the Cell Cd$\mathrm{Hg} / \mathrm{CdCl} 2(\mathrm{~m}) / \mathrm{AgCl} / \mathrm{Ag}$ at $25^{\circ}$. J. Am. Chem. Soc. 1958, 80, 5048-5050.

(61) Kivalo, P.; Ekari, P. A polarographic study of the bromocomplexes of cadmium. Variation of the stability constant with ionic strength. Suomen Kem. B 1957, 30, 116-120. 
(62) Bates, R. G. The Thermodynamics of Bi-univalent Electrolytes. IV. Cadmium Bromide in Aqueous Solution. J. Am. Chem. Soc. 1939, 61, 308-315.

(63) Lutfullah,; Paterson, R. Stability constants for cadmium iodide complexes in aqueous cadmium iodide (298.15 K). J. Chem. Soc. Faraday Trans. I 1978, 74, 484-489.

(64) Prausnitz, J. M.; Lichtenthaler, R. N.; de Azevedo, E. G. Molecular thermodynamics of fluid-phase equilibria; Prentice Hall, 1999.

(65) Blum, L.; Høye, J. Mean spherical model for asymmetric electrolytes. 2. Thermodynamic properties and the pair correlation function. J. Phys. Chem. 1977, 81, 1311-1316.

(66) Blum, L. In Theoretical Chemistry, Advances and Perspectives; Eyring, H., Henderson, D., Eds.; Academic Press: New York, 1980; Vol. 5.

(67) Simonin, J.-P. Study of experimental-to-McMillan-Mayer conversion of thermodynamic excess functions. J. Chem. Soc. Faraday Trans. 1996, 92, 3519-3523.

(68) Simonin, J.-P.; Blum, L.; Turq, P. Real Ionic Solutions in the Mean Spherical Approximation. 1. Simple Salts in the Primitive Model. J. Phys. Chem. 1996, 100, 7704-7709.

(69) Simonin, J.-P. Real Ionic Solutions in the Mean Spherical Approximation. 2. Pure Strong Electrolytes up to Very High Concentrations, and Mixtures, in the Primitive Model. J. Phys. Chem. B 1997, 101, 4313-4320.

(70) Jones, M. M.; Jones, E. A.; Harmon, D. F.; Semmes, R. T. A search for perchlorate complexes. Raman spectra of perchlorate solutions. J. Am. Chem. Soc. 1961, 83, 20382042.

(71) Shannon, R. Revised effective ionic radii and systematic studies of interatomic distances in halides and chalcogenides. Acta Cryst. A 1976, 32, 751-767.

(72) Goldberg, R.; Manley, J.; Nuttal, R. Program Gamphi for Calculating Activity and Osmotic Coefficients of Aqueous Electrolyte Solutions at 298.15 K. 1984. 
(73) Novotny, P.; Sohnel, O. Densities of binary aqueous solutions of 306 inorganic substances. J. Chem. Eng. Data 1988, 33, 49-55.

(74) D'Ans, J.; Surawski, H.; Synowietz, C. Densities of binary aqueous systems and heat capacities of liquid systems. Landolt-Börnstein database: Numerical Data and Functional Relationships in Science and Technology. Group IV: Macroscopic and Technical Properties of Matter; Springer Berlin, Heidelberg, New York, 1977; Vol. 1.

(75) Reilly, P.; Stokes, R. The diffusion coefficients of cadmium chloride and cadmium perchlorate in water at $25^{\circ}$. Aust. J. Chem. 1971, 24, 1361-1367.

(76) Timmermans, J. The Physico-chemical Constants of Binary Systems in Concentrated Solutions: Systems with metallic compounds; Interscience publishers, 1960; Vol. 3.

(77) Robinson, R. A thermodynamic study of bivalent metal halides in aqueous solution. Part V. The activity coefficients of cadmium chloride and bromide at $25^{\circ} \mathrm{C}$. Trans. Faraday Soc. 1940, 36, 1135-1136.

(78) Bockris, J. O.; Reddy, A. K. Modern Electrochemistry; Kluwer, 2002; Vol. 1.

(79) Jenkins, H.; Thakur, K. Reappraisal of thermochemical radii for complex ions. J. Chem. Educ 1979, 56, 576.

(80) Huheey, J. E.; Keiter, E. A.; Keiter, R. L.; Medhi, O. K. Inorganic chemistry: principles of structure and reactivity; Pearson Education India, 2006.

(81) Schatzberg, P. Molecular diameter of water from solubility and diffusion measurements. J. Phys. Chem. 1967, 71, 4569-4570.

(82) Ben-Naim, A. In The Physics and Physical Chemistry of Water; Franks, F., Ed.; Springer New York: Boston, MA, 1972; pp 413-442. 
(83) Ruas, A.; Moisy, P.; Simonin, J.-P.; Bernard, O.; Dufrêche, J.-F.; Turq, P. Lanthanide salts solutions: Representation of osmotic coefficients within the binding mean spherical approximation. J. Phys. Chem. B 2005, 109, 5243-5248.

(84) Vilariño, T.; Bernard, O.; Simonin, J.-P. Ionic solutions in the binding mean spherical approximation. Thermodynamics of associating electrolytes up to very high concentrations. J. Phys. Chem. B 2004, 108, 5763-5770.

(85) Barthel, J.; Krienke, H.; Neueder, R.; Holovko, M. The role of ion-aggregate formation in the calculation of physical properties of electrolyte solutions. Fluid Phase Equilib. 2002, 194, 107-122. 


\section{Abstract Graphic}

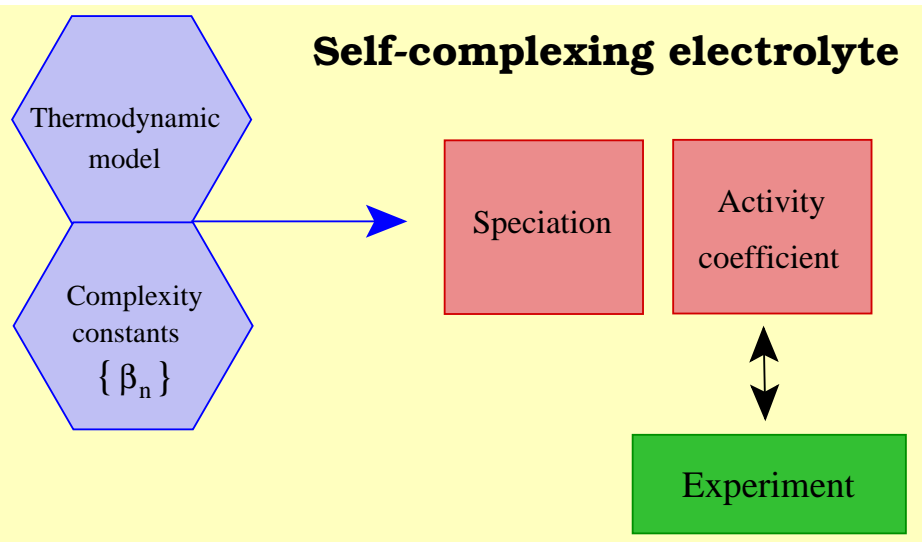




\title{
Supporting Information
}

\section{Thermodynamic consistency in the modeling of speciation in self-complexing electrolytes}

\author{
Jean-Pierre Simonin*,†, \\ †CNRS, UMR 8234, PHENIX, F-75005, Paris, France. \\ $\ddagger$ Laboratoire PHENIX, Sorbonne Universités, UPMC Univ Paris 06, UMR 8234, \\ Université P.M. Curie, F-75005, Paris, France. \\ E-mail: jpsimonin@gmail.com
}




\section{Mean salt activity coefficient values of $\mathrm{ZnI}_{2}$ computed using the Davies equation}

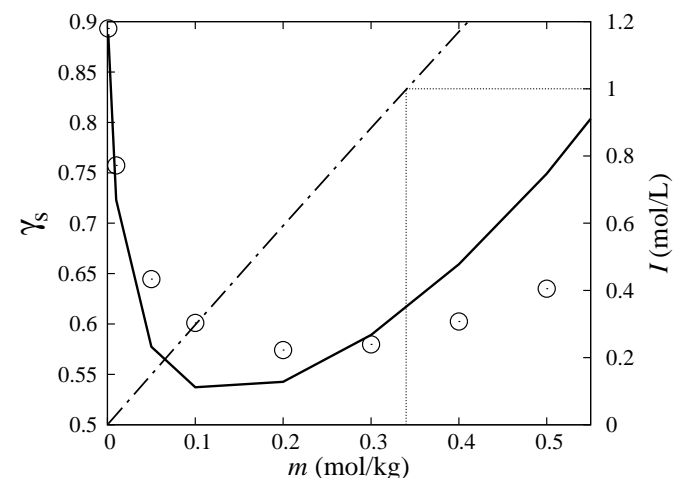

Figure S1: $\mathrm{ZnI}_{2}$. Experimental and calculated values of mean salt activity coefficient, and ionic strength, as a function of molality, for $a=0.3$ (solid line). Dash-dotted line: ionic strength (right-hand scale). The molality at which $I=1 \mathrm{~mol} \mathrm{~L}^{-1}$ is indicated with dotted straight lines.

\section{Mean salt activity coefficient values of $\mathrm{ZnCl}_{2}$ computed using the Specific Interaction Theory (SIT)}

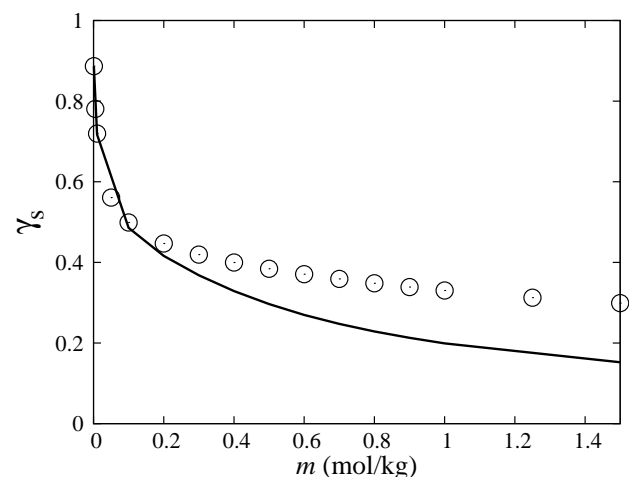

Figure $\mathrm{S} 2: \mathrm{ZnCl}_{2}$. Experimental data $(\odot)$ for mean salt activity coefficient as a function of molality, and values calculated using the Specific Interaction Theory (SIT) (solid line). 


\section{Mean salt activity coefficient values of $\mathrm{ZnI}_{2}$ computed using the MSA model}

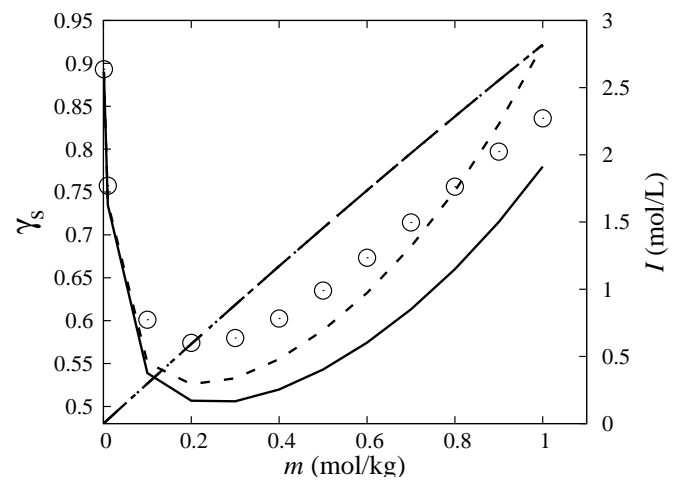

Figure S3: $\mathrm{ZnI}_{2}$. Experimental $(\odot)$ and calculated MSA values of mean salt activity coefficient, and ionic strength, as a function of molality. Solid line: MSA result for minimum values of diameters; dotted line: idem for maximum values of diameters (see text). Dashdotted line: ionic strength (right-hand scale) for the minimum (and maximum) values of all diameters.

\section{Speciation in solutions of zinc chloride}

The plots below show the calculated proportions of complexes in solutions of $\mathrm{ZnCl}_{2}$ for $n=2,3$ and 4 . 


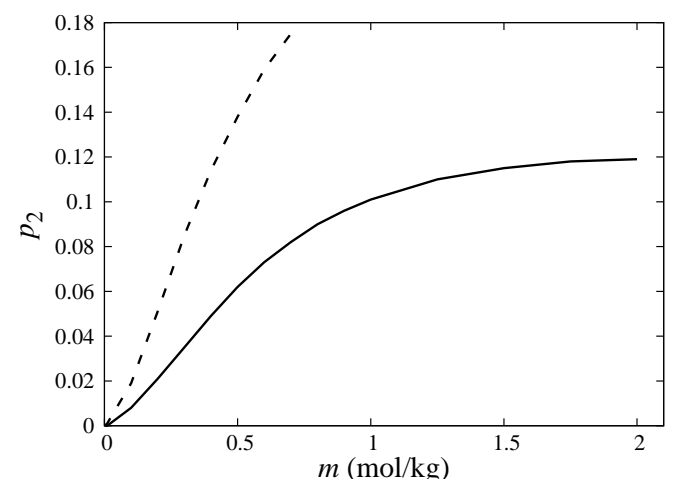

Figure S4: Proportion of complex $\mathrm{ZnCl}_{2} \mathrm{~W}_{4}^{0}, p_{2}$, in $\mathrm{ZnCl}_{2}$ solutions as a function of molality. Solid line $=$ MSA result with $\beta_{n}$ values of Table 6 ; dashed line $=$ result using the Davies equation with the $\beta_{n}$ values taken by CHEAQS (Table 2 ) for $I<1 \mathrm{M}$.

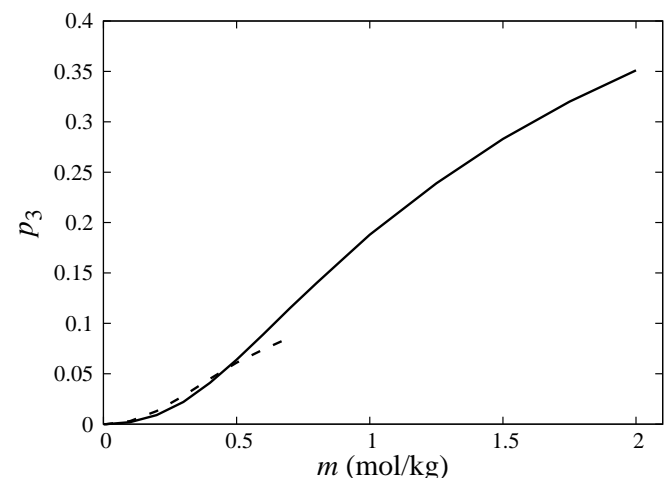

Figure S5: Same legend as in Figure $\mathrm{S} 4$ for the proportion of complex $\mathrm{ZnCl}_{3} \mathrm{~W}^{-}, p_{3}$.

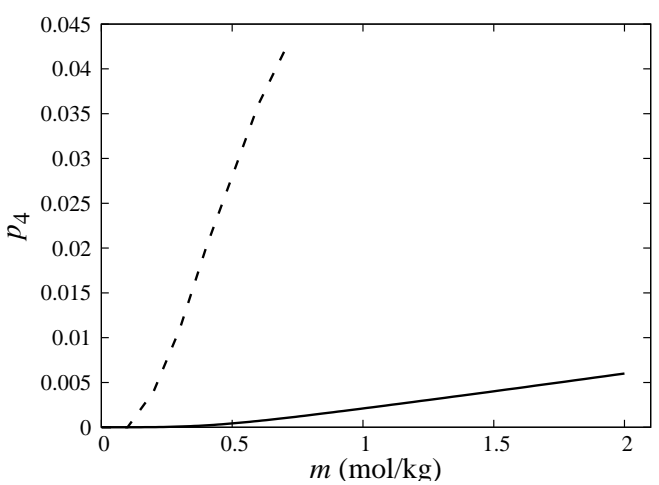

Figure S6: Same legend as in Figure S4 for the proportion of complex $\mathrm{ZnCl}_{4}^{2-}, p_{4}$. 